NBER WORKING PAPER SERIES

\title{
GETTING BETTER OR FEELING BETTER? HOW EQUITY INVESTORS RESPOND TO INVESTMENT EXPERIENCE
}

\author{
John Y. Campbell \\ Tarun Ramadorai \\ Benjamin Ranish \\ Working Paper 20000 \\ http://www.nber.org/papers/w20000 \\ NATIONAL BUREAU OF ECONOMIC RESEARCH \\ 1050 Massachusetts Avenue \\ Cambridge, MA 02138 \\ March 2014
}

The first version of this paper was circulated under the title "Getting Better: Learning to Invest in an Emerging Stock Market". We gratefully acknowledge NSDL and SEBI for providing us with access to the data, the Sloan Foundation for financial support, and the use of the University of Oxford Advanced Research Computing (ARC) facility. We thank Samar Banwat, Chandrashekhar Bhave, Gavin Boyle, Stefano Della Vigna, Luigi Guiso, Michael Haliassos, Matti Keloharju, Ralph Koijen, Stefan Nagel, Nagendar Parakh, Prabhakar Patil, Gagan Rai, G V Nageswara Rao, Enrichetta Ravina, Renuka Sane, Manoj Sathe, Ajay Shah, Tyler Shumway, U.K. Sinha, Jayesh Sule, seminar participants at NSDL, SEBI, NIPFP, NSE, the Einaudi Institute, EDHEC, the Oxford-Man Institute, the IGIDR Emerging Markets Finance Conference, the NBER Household Finance and Behavioural Economics Groups, and the Sloan-Russell Sage Working Group on Behavioral Economics and Consumer Finance for many useful comments, and Vimal Balasubramaniam and Sushant Vale for excellent and dedicated research assistance. The opinions expressed in this paper are those of the authors and do not necessarily reflect the views of the Board of Governors, other employees of the Federal Reserve System, or the National Bureau of Economic Research.

At least one co-author has disclosed a financial relationship of potential relevance for this research. Further information is available online at http://www.nber.org/papers/w20000.ack

NBER working papers are circulated for discussion and comment purposes. They have not been peerreviewed or been subject to the review by the NBER Board of Directors that accompanies official NBER publications.

(C) 2014 by John Y. Campbell, Tarun Ramadorai, and Benjamin Ranish. All rights reserved. Short sections of text, not to exceed two paragraphs, may be quoted without explicit permission provided that full credit, including (C) notice, is given to the source. 
Getting Better or Feeling Better? How Equity Investors Respond to Investment Experience John Y. Campbell, Tarun Ramadorai, and Benjamin Ranish

NBER Working Paper No. 20000

March 2014

JEL No. G11

\begin{abstract}
$\underline{\text { ABSTRACT }}$
Using a large representative sample of Indian retail equity investors, many of them new to the stock market, we show that both years of investment experience and feedback from investment returns have significant effects on investor behavior, favored stock styles, and performance. We identify two channels of feedback: performance relative to the market, and the directly experienced returns to behavior and styles of stock. Both of these vary across investors at a point in time because investors are imperfectly diversified and receive idiosyncratic returns. We find that experienced investors generally behave in a manner more consistent with the recommendations of finance theory, although this tendency is weakened by strong investment performance. High trading profits increase turnover, while high returns to equity styles have a short-term negative and a longer-term positive effect on investors' style demands, possibly reflecting the offsetting effects of disposition bias and style chasing. We document high returns on a portfolio of stocks held by experienced investors, and on individual Indian stocks with an experienced and low-turnover investor base.
\end{abstract}

John Y. Campbell

Morton L. and Carole S.

Olshan Professor of Economics

Department of Economics

Harvard University

Littauer Center 213

Cambridge, MA 02138

and NBER

john_campbell@harvard.edu

Tarun Ramadorai

University of Oxford

Said Business School

Park End St.

Oxford OX1 1HP

United Kingdom

tarun.ramadorai@sbs.ox.ac.uk
Benjamin Ranish

Federal Reserve Board of Governors

Washington, DC 20006

ben.ranish@frb.gov

An online appendix is available at:

http://www.nber.org/data-appendix/w20000 
It's a little better all the time. (It can't get no worse.)

Lennon and McCartney, "Getting Better," 1967.

\section{Introduction}

In this paper, using comprehensive data on the holdings, trades, and returns of Indian stock market participants, we analyze how retail investors respond to the investment experience they gain from participation. This experience affects investment behavior, specifically underdiversification, turnover, and disposition bias; demands for small-cap, value, and momentum equity styles; and investor performance. We measure experience not only from the time since investors first begin participating in the equity market, but also by exploiting cross-sectional variation in directly experienced feedback that investors receive from the performance of their overall portfolios and of specific behaviors and styles. The latter source of identification is novel, exploiting the imperfect diversification of retail investor portfolios and the resulting idiosyncratic variation in experienced returns. Using these identification strategies, we find that strong overall investment performance encourages aggressive behaviors with potentially deleterious consequences in the longer run, while strong performance of style-representative stocks within investors' portfolios induces short-run decumulation and longer-run accumulation of these styles. These results may reflect reinforcement learning, with investors "feeling better" after positive feedback and repeating behaviors they associate with the feedback. Despite these consequences of positive feedback, we find that more experienced Indian retail investors generally behave more in line with the recommendations of finance theory, "getting better" at investing over time.

Equity investing is an important task for households accumulating financial assets. Because stocks have historically offered a risk premium, households with no initial exposure to the asset class can benefit from holding at least some stocks. The optimal equity allocation depends on market conditions, the equity premium, and many details of the household's financial situation, including the household's risk aversion and other risk exposures, but typical normative calibrations suggest it is substantial - at least for households with sufficient 
wealth to justify paying the fixed cost of equity market participation (Campbell and Viceira 2002, Campbell 2006, Siegel 2007, Gomes and Michaelides 2008). Investing in stocks is not straightforward, however, and households can lose much of the benefit of stock market participation if they engage in certain investment behaviors that appear to be quite prevalent.

Three such investment behaviors can be costly even in a market where all individual stocks have the same risk and the same expected return. First, underdiversification increases portfolio risk without increasing return (Blume and Friend 1975, Kelly 1995, Calvet et al. 2007). Second, high turnover of an equity portfolio leads to high trading costs (Odean 1999, Barber and Odean 2000). Third, selling stocks that have appreciated while holding those that have depreciated - a tendency known as the disposition effect-increases the present value of tax obligations by accelerating the realization of capital gains and deferring the realization of offsetting losses (Shefrin and Statman 1985, Odean 1998). In a market where expected returns differ across stocks, it is also possible for households to lose by picking underperforming stocks. They may do this by taking risk exposures that are negatively compensated, for example by holding growth stocks in a market with a value premium, or by adopting a short-term contrarian investment strategy (perhaps driven by the disposition effect) in a market with momentum where outperforming stocks continue to outperform for a period of time. If these style tilts do not offset other risks of the household, they are welfare reducing. ${ }^{2}$ Alternatively, households may lose by trading with informed counterparties in a market that is not strong-form efficient, and thus rewards investors who possess private information (Grossman and Stiglitz 1980, O'Hara 2003).

One response to the challenges of direct equity investing is for households to hold mutual funds, thereby gaining equity exposure without trading stocks directly. This, however, may result in trade-offs between households' tendencies to engage in suboptimal behaviors, the

\footnotetext{
${ }^{2}$ This is true whether risk prices are driven by fundamentals or by investor sentiment (the preferences of unsophisticated investors for certain types of stocks). In a market where fundamentals determine risk prices it may be more likely that households' non-equity risk exposures justify equity positions with low expected returns, but if this is not the case such positions still reduce household welfare just as they would in a sentiment-driven model.
} 
level of fees charged by intermediaries, and the possibility that mutual fund managers may themselves be susceptible to these behaviors. That delegation is not a magic bullet for retail investors is also reflected in the direction in which the extensive literature on behavioral finance has evolved over the years, moving away from the simple characterization of institutions as "smart money" and retail investors as "dumb money". Findings of an unequal distribution of ability in institutional money management, and the constraints imposed on institutions by agency problems, limits to arbitrage, and peer benchmarking have been complemented by findings that an appreciable fraction of retail investors appear to outperform in equity markets.

Empirically, direct equity investing remains important for many households. Because direct equity investing can have significant benefits but also substantial costs, depending on implementation, it is important to understand how households learn to perform this function. Several recent papers have explored the way in which equity investors respond to experience (Nicolosi et al. 2009, Seru et al. 2010, Malmendier and Nagel 2011, 2012). An optimistic view is that even if households make investment mistakes initially, they rapidly learn to avoid these mistakes, "getting better" in the words of Lennon and McCartney. A more pessimistic view is that households overreact to random personal experiences, in an attempt to "feel better" by repeating investment behaviors or investing in styles that happen to have performed well for them in the recent past. The optimistic view emphasizes the potential benefits of rational Bayesian learning, while the pessimistic view emphasizes the potentially perverse effects of reinforcement learning in which salient but random personal experiences are overweighted relative to broader patterns of evidence in historical data.

The Indian market that we study in this paper is for several reasons an ideal laboratory for studying learning among equity investors. First, India is an emerging market whose capitalization and investor base have been growing rapidly. In such a population of relatively inexperienced investors, learning may be faster and easier to detect than in better established equity markets. Second, as discussed more fully below, mutual funds account for a relatively small value share of Indian individuals' equity exposure. This has several important implications. Most obviously, it is meaningful to measure the diversification of 
directly held stock portfolios. The prevalence of direct equity ownership also implies that it is more important for Indian investors to develop the skills necessary to own stocks directly than it is in a mature market with a large mutual fund share. Third, and most importantly for our purposes, underdiversification of directly held Indian stock portfolios creates a rich cross-section of investment experiences that we can use to identify how investors learn about aspects of investing such as differences in expected returns across categories of stocks, and the benefits or costs of engaging in certain investment behaviors. Because investors in the same cohort have idiosyncratic experiences, this source of identification is different from the variation in experience across cohorts exploited by Malmendier and Nagel (2011, 2012). Finally, India has electronic registration of equity ownership, allowing us to track the complete ownership history of listed Indian stocks over a decade. The relatively long time dimension of our panel allows us to measure investors' performance using realized returns, a method that is vulnerable to common shocks when applied to a short panel. Moreover, our data are monthly, and this relatively high frequency allows us to more accurately measure momentum investing and turnover.

The benefits of Indian data do come with some limitations - the most serious one is that we have almost no information about the demographic characteristics of investors. Thus we cannot follow the strategies, common in household finance, of proxying financial sophistication using information about investors' age, education, and occupation (Calvet et al. 2007, 2009a, Betermier et al. 2013), their IQ test scores (Grinblatt and Keloharju 2011), or survey evidence about their financial literacy (Lusardi and Mitchell 2007). Instead, we study learning by relating the behavior and investment performance of each investor to account age (the length of time since stocks were first held in an account) and measurements of past behavior and performance.

We measure feedback in two ways. The broader source of feedback that we consider is the overall past account performance of an investor relative to the market. We also construct more specific measures of feedback for each behavior and style tilt that we study. For example, each month investors receive new feedback regarding the desirability of portfolio turnover from the comparison between their actual investment returns and the returns they 
would have received had they stopped trading three months earlier and moved to a buyand-hold strategy. Similarly, each month investors receive feedback on the desirability of a style tilt, for example towards value, from the differences in the returns of stocks in their portfolios which are positively style-tilted (value stocks), and those that are negatively styletilted (growth stocks). In this way we can measure investors' response to style returns at the idiosyncratic rather than the aggregate level. Our use of this idiosyncratic variation in directly experienced feedback to identify investor responses contrasts with much of the literature (including Froot, O'Connell, and Seasholes 2001, and Campbell, Ramadorai, and Schwartz 2009), which identifies positive-feedback trading behavior using aggregate style returns. As aggregate style returns are potentially correlated with a range of unobserved time-series variables, the investor-specific variation in observed style returns that we exploit allows for relatively sharp identification.

Our main results are as follows. Considering investment behaviors first, we find that both turnover and the disposition effect decline substantially with account age. Over the first eight years of investing experience, controlling for feedback, we find that turnover falls by $84 \%$ and the disposition effect by $52 \%$ relative to their mean levels. However there is little effect of age on the idiosyncratic share of retail investors' portfolio variance. Overall account performance appears to encourage aggressive investment behavior: less diversification, heavier trading, and a greater disposition effect. However these effects are short-lived, dying out after one or two quarters. We find that behavior-specific feedback has a significant and highly persistent impact on turnover, but little impact on the disposition effect.

Investors' style tilts are also significantly affected by both overall time spent in the market and feedback. We find that experienced investors have a strong tendency to accumulate value stocks and a more modest tendency to accumulate small stocks. The effect of experience on the accumulation of momentum stocks is non-monotonic, as both novice and extremely experienced investors favor momentum stocks slightly more than investors with two to five years of investment experience. Feedback also has important effects on the style tilts of Indian retail investors. We find that investors who achieve high overall returns tend to accumulate large, growth, and high momentum stocks. In the short term, we find that 
investors decumulate styles that have recently outperformed within their portfolios, in a manner consistent with the disposition effect. However, we find a smaller but far longerlived tendency to accumulate or "chase" styles in which investors have experienced positive returns. Such style chasing behavior is a feature of several theoretical models, most notably that of Barberis and Shleifer (2003), although it has been difficult to find well-identified effects of directly experienced feedback on investing behavior.

Account age and feedback ultimately affect retail investor performance both through their impacts on measured behavior and style tilts, and through other channels that we do not measure directly. Experienced investors appear to have substantially higher returns than novice investors, although this result is imprecisely estimated. Investors who behave like experienced investors - those with low turnover and a low disposition effect - perform better with and without controls for standard risk factors. Experienced Indian investors tend to tilt their portfolios towards the type of stocks which have higher returns: small stocks, low turnover stocks, and stocks held by institutions. Experienced Indian investors are also more likely to avoid large, attention-grabbing initial public offerings. The effects of investor experience can also be detected in the cross-section of Indian stock returns. Controlling for stock characteristics and factor loadings, characteristics of Indian stocks' investor base can be used to predict their returns. Indian stocks held by more experienced investors, investors with low portfolio turnover, and investors with value tilts have significantly positive returns unexplained by standard factors and characteristics.

The organization of the paper is as follows. Section 2 describes our data, defines the empirical proxies we use for investment mistakes and style tilts, and presents some summary statistics. Section 3 presents our methodology for estimating age and feedback effects. Section 4 applies this methodology to estimate age and feedback effects on behavior, while Section 5 applies it to age and feedback effects on style tilts. Section 6 draws implications for individuals' account performance given their behavior and the performance of stocks given the behavior of their investor base. Section 7 concludes. 


\subsection{Related Literature}

The behavior of individual investors in equity markets has been of interest to financial economists studying market efficiency since the efficient markets hypothesis was first formulated. Shleifer (2000) summarizes the importance of this line of inquiry for the study of market efficiency, outlining that theoretical defenses of the efficient markets hypothesis rely on at least one of three concepts. The first is rational decision making and securities valuation by individuals, the second, the absence of correlated deviations from rationality even if some investors deviate from rational decision making, and the third, limits to arbitrage.

Understanding the behavior of individual investors is also important for the field of household finance (see Campbell 2006, for example). There has been much work on theoretically optimal investment in risky assets, and deviations from such idealized behavior by households have important implications for the evolution of the wealth distribution in the economy.

While the theoretical motivation for the study of individual investors has been clear for some time, empirical work has been hampered by the difficulty of obtaining detailed data on individual investors' portfolios and the computational burden imposed by the study of such large datasets. These constraints have gradually been surmounted, and this field is now one of the most active areas of empirical finance research.

Early work in the area (Cohn et al. 1975, Schlarbaum et al. 1978, Badrinath and Lewellen 1991) used relatively small samples of trader accounts from retail or discount brokerages to shed light on the stocks held by individual investors, the returns they earned, and the practice of tax-loss selling. The first set of empirical studies with a primary focus on questions related to rationality and market efficiency followed in the late 1990s, also using data sourced from discount brokerages, identifying that individual investors exhibit the disposition effect (Odean 1998), and trade excessively in the sense that their transactions costs outweigh any stock-picking ability they may possess (Odean 1999, Barber and Odean 2000). These tendencies were found to vary with the demographic characteristics and trading technologies of investors such as gender, marital status, and access to online trading (Barber and Odean 2001, 2002). A related focus has been on characterizing the trading strategies of individual 
investors through the lens of various behavioral biases such as the disposition effect, overconfidence, or inattention (see, for example, Barber and Odean 2008 and references above), and demonstrating the types of stocks (large, hard-to-value) in which these biases are most likely to manifest themselves (Ranguelova 2001, Kumar 2009).

A characteristic of this early literature, and continuing to the present day, is the focus on trading rather than investment decisions of individual investors. While many questions in household finance are about the performance and risk properties of the entire risky asset portfolio of individual households, much of the literature has concentrated on performance evaluation of individual investors' purchases and sales at different post-trade horizons (see, for example, Coval et al. 2005, Barber et al. 2008, Seru et al. 2010), and on contrasting individual returns with those achieved by domestic and foreign institutional investors (Grinblatt and Keloharju 2000, Kaniel et al. 2008). Several of these studies arrive at the conclusion that treating individual investors as a monolithic entity may be misleading, as there are detectable differences in performance in the cross-section of investors. Most recently, Kelley and Tetlock (2013) suggest that learning by retail investors may be one promising explanation of such variation - our findings on variations in behavior, style tilts, and performance in the cross-section of Indian retail investors are consonant with this line of thinking, albeit distinguished by our emphasis on investment rather than trades.

The literature's focus on trading arises naturally from the limitations of the data used to study investor behavior. In the US, discount brokerage accounts from a single service provider may not be truly representative of the entire portfolio of an individual investor, a problem made significantly worse when investors also have untracked mutual fund or 401(k) investments. $^{3} \quad$ And some international datasets, such as the Taiwanese stock exchange data used by Barber et al. (2008), track all individual investor transactions but have little detail on holdings. Our use of Indian data on direct equity holdings and trades helps us to partially surmount this obstacle. We have a relatively high-quality proxy for total household investment in stocks, because equity mutual fund ownership by individual investors in India

\footnotetext{
${ }^{3}$ Calvet et al. (2007), show that mutual fund investments are an important source of diversification for Swedish investors.
} 
is much smaller than direct equity ownership. As detailed in the internet appendix, we estimate that Indian households' equity mutual fund holdings are between $6 \%$ and $19 \%$ of their direct equity holdings over our sample period.

There are some other countries, such as Sweden and Finland, in which both direct equity ownership and mutual fund holdings are tracked. In principle this allows for a fuller characterization of household investment, but most previous studies using data from these countries have pursued different objectives than our focus on learning to invest. For example, Grinblatt et al. (2011) show that IQ affects stock market participation using data from the Finnish registry which provides detailed information on direct equity portfolios combined with an indicator for whether the household invested in mutual funds in the year 2000. Grinblatt et al. (2012) highlight the impacts of IQ on mutual fund choice by Finnish investors using detailed data on mutual fund choices alongside less detailed information on direct equity investment. Calvet et al. (2007, 2009) use comprehensive data on Swedish investors' total wealth to shed light on stock-market participation and portfolio rebalancing, and a recent study by Betermier et al. (2013) examines the value tilt of Swedish investors, finding a tendency for this tilt to increase over the life cycle. However the annual frequency of the Swedish data makes it difficult for them to evaluate higher-frequency phenomena such as momentum investing and turnover.

Several papers, including those referenced in the previous section, share our focus on learning by individual investors, but emphasize different facets of this important issue. Feng and Seasholes (2005) use data on over 1500 individual accounts from China over the 1999 to 2000 period, and find that both experience (measured by the number of positions taken) and sophistication (measured by variables that include idiosyncratic variance) attenuate the disposition effect. Our analysis differs from theirs in our use of a more comprehensive set of investor behaviors and our exploration of feedback effects on future investing behavior.

Linnainmaa (2010) estimates a structural model of learning and trading by investors in Finland, focusing on high-frequency traders, who make at least one round-trip trade in a given day. He finds, intriguingly, that traders appear to experiment with high-frequency trading to better understand their levels of skill, and cease trading if they experience poor 
returns. Our estimated feedback effects on underdiversification suggest that households also experiment with the composition of their equity portfolios, choosing to underdiversify more aggressively if they beat the market.

This finding of experimentation is also consistent with Seru et al. (2010), who carefully study the trading behavior of Finnish investors, focusing on the disposition effect. Seru et al. find that investors stop trading ("exit") after inferring that their ability is poor, and that trading experience weakens the disposition effect. ${ }^{4}$ Our work is distinguished from this literature by our focus on investments rather than trades, and our analysis of style tilts in addition to behaviors such as the disposition effect. It is worth noting that "exit" in our setting is the relatively uncommon exit of an investor from all equity positions, whereas Seru et al. use this term to refer to a period of time during which no trading occurs.

Goetzmann and Massa (2002) identify both positive- and negative-feedback investing in a cross-section of 91,000 investor accounts in an S\&P 500 index fund, but do not consider stylechasing behavior specifically. Recent work by Huang (2013) documents that US households with discount brokerage accounts react to outperformance within an industry by increasing their probability of purchasing new stocks in that industry. This result is similar to our finding of style-chasing behavior among Indian investors.

Several papers have documented household reinforcement learning in other settings, such as investment in IPOs (Kaustia and Knüpfer 2008, Chiang et al. 2011) and household choice of credit cards (Agarwal et al., 2006, 2008). Agarwal et al. (2008) find that households learn how best to reduce fees on their credit card bills, and estimate that knowledge depreciates by roughly $10 \%$ per month, i.e., they find evidence that households learn and subsequently forget. In a similar spirit our empirical specification allows us to compare the short- and long-run effects of investment performance feedback on household investment decisions.

Finally, there is a parallel literature measuring the effects of experience and feedback on the decisions of professional investors. Institutional investors' feedback trading behavior

\footnotetext{
${ }^{4}$ Related work on the positive effect of trader experimentation and trader experience on returns and bias attenuation includes Dhar and Zhu (2006), Mahani and Bernhardt (2007), and Nicolosi et al. (2009). Korniotis and Kumar (2011), in contrast, find that the adverse effects of aging dominate the positive effects of experience.
} 
has been studied by a range of authors including Froot, O'Connell, and Seasholes (2001), Froot and Teo (2008), and Campbell, Ramadorai, and Schwartz (2009) - our analysis is distinguished from these by our use of cross-sectional variation in the directly experienced performance of styles rather than the use of aggregate style returns. Greenwood and Nagel (2009) document trend following by mutual fund managers during the technology boom, which is stronger for younger managers. Kempf, Manconi, and Spalt (2013) show that mutual fund managers perform better in industries where they have more years of investment experience.

\section{Data and Summary Statistics}

\subsection{Electronic stock ownership records}

Our data come from India's National Securities Depository Limited (NSDL), with the approval of the Securities and Exchange Board of India (SEBI), the apex capital markets regulator in India. NSDL was established in 1996 to promote dematerialization, that is, the transition of equity ownership from physical stock certificates to electronic records of ownership. It is the older of the two depositories in India, and has a significantly larger market share (in terms of total assets tracked, roughly $80 \%$, and in terms of the number of accounts, roughly $60 \%$ ) than the other depository, namely, Central Depository Services Limited (CDSL). NSDL's share of individual accounts by state tends to be slightly greater in wealthier urban states, but has the majority of the depository market in most areas.

While equity securities in India can be held in both dematerialized and physical form, settlement of all market trades in listed securities in dematerialized form is compulsory. To facilitate the transition from the physical holding of securities, the stock exchanges do provide an additional trading window, which gives a one time facility for small investors to sell up to 500 physical shares; however the buyer of these shares has to dematerialize such shares before selling them again, thus ensuring their eventual dematerialization. Statistics from the Bombay Stock Exchange (BSE) and the National Stock Exchange (NSE) highlight 
that virtually all stock transactions take place in dematerialized form.

We do not observe data on the derivatives transactions of Indian investors, including their participation in single-stock futures markets (in which open interest and trading volume are both larger than the stock index futures market, see, for example, Vashishtha and Kumar 2010). However, there is evidence that trading volume on Indian stock futures is very highly correlated with trading volume in the corresponding underlying equity security (Martins, Singh, and Bhattacharya 2012), suggesting that the patterns that we uncover will not be greatly affected by the absence of these data.

The sensitive nature of our data mean that there are certain limitations on the demographic information provided to us. While we are able to identify monthly stock holdings and transactions records at the account level in all equity securities on the Indian markets, we have sparse demographic information on the account holders. The information we do have includes the state in which the investor is located, whether the investor is located in an urban, rural, or semi-urban part of the state, and the type of investor. We use investor type to classify accounts as beneficial owners, domestic financial institutions, domestic non-financial institutions, foreign institutions, foreign nationals, government, and individual accounts. ${ }^{5}$ This paper studies only the category of individual accounts.

A single investor can hold multiple accounts on NSDL; however, a requirement for account opening is that the investor provides a Permanent Account Number (PAN) with each account. The PAN is a unique identifier issued to all taxpayers by the Income Tax Department of India. NSDL provided us with a mapping from PANs to accounts, so in our empirical work, we aggregate all individual accounts associated with a single PAN. PAN aggregation reduces the total number of individual accounts in our database from about 13.7 million to 11.6 million. It is worth noting here that PAN aggregation may not always correspond to household aggregation if a household has several PAN numbers, for example, if children or

\footnotetext{
${ }^{5}$ We classify any account which holds greater than $5 \%$ of an stock with market capitalization above 500 million Rs (approximately $\$ 10$ million) as a beneficial owner account if that account would otherwise be classified as a trust, "body corporate," or individual account. This separates accounts with significant control rights from standard investment accounts. Otherwise our account classifications are many-to-one mappings based on the detailed investor types we observe.
} 
spouses have separate PANs. In addition it is possible that there may be households in our NSDL data who also have depository accounts with CDSL, which we do not observe. Conversations with our data provider suggest, however, that the fraction of retail investors with such multiple depository relationships is small, and that depository relationships tend to be persistent. ${ }^{6}$

Table 1 summarizes the coverage of the NSDL dataset. The first two columns report the total number of securities (unique International Securities Identification Numbers or ISIN) and the total number of Indian equities reported in each year. Securities coverage grows considerably over time from just 12,350 in 2004 to almost 23,000 in 2011, as does the number of unique Indian equities covered. Starting at 4,533 in 2004, the number of equities reaches a peak of 7,735 in 2012 . When we match these data to price, returns, and corporate finance information from various datasets, we are able to match between $96 \%$ and $98 \%$ of the market capitalization of these equities, and roughly the same fraction of the individual investor ownership share each year. The third column shows the market capitalization of the BSE at the end of each year. The dramatic variation in the series reflects both an Indian boom in the mid-2000s, and the impact of the global financial crisis in 2008.

The fourth column of Table 1 shows the fraction of Indian equity market capitalization that is held in NSDL accounts. The NSDL share grows from just above $50 \%$ at the beginning of our sample period to about $70 \%$ at the end. The fifth column reports the fraction of NSDL market capitalization that is held in individual accounts. The individual share starts at about $18 \%$ in 2004, but declines to just below $10 \%$ in 2012, reflecting changes in NSDL coverage of institutions, as well as an increase in institutional investment over our sample period. The sixth column shows the mutual fund share of total equities, which accounts for a little over $3.5 \%$ of total assets in the NSDL data in 2004, growing to a maximum of $4.72 \%$ in 2006 , and declining to $3.97 \%$ by 2012 . While comparing the fifth and sixth columns of Table 1 demonstrates the magnitude of direct household equity ownership relative to mutual

\footnotetext{
${ }^{6}$ Moreover, in the absence of the unlikely scenarios of substantial negative correlation in trading in crossdepository accounts, or movement of trading activity from one depository account to the other conditional on experience or feedback, we would not expect this issue to importantly affect our inferences.
} 
funds, this simple comparison would lead to an overestimate of mutual fund ownership by households. SEBI data in 2010 show that roughly $60 \%$ of mutual funds in India are held by corporations. $^{7}$ In the internet appendix (Campbell, Ramadorai, and Ranish 2014), we estimate that individuals' indirect equity holdings through mutual funds, unit trusts, and unit-linked insurance plans were between $6 \%$ and $19 \%$ of total household equity holdings over the sample period. We note also that a 2009 SEBI survey of Indian equity-owning households found that about $65 \%$ of such households did not own any bonds or mutual funds.

From the beginning to the end of our sample period, the number of individual NSDL accounts grew from 2.7 million to roughly 6.1 million, that is, by $125 \%$. While equity ownership expanded throughout the decade, the growth is correlated with the return on the aggregate Indian market (illustrated by the dashed line in internet appendix Figure A1). Growth was particularly rapid in 2004 and 2007, and much slower in the period since the onset of the global financial crisis.

\subsection{Characteristics of individual accounts}

Table 2 describes some basic characteristics of Indian individual accounts. Because this dataset is an unbalanced panel, with accounts entering and exiting over time, we summarize it in two ways. The first set of three columns reports time-series moments of cross-sectional means. The first column is the time-series mean of the cross-sectional means, which gives equal weight to each month regardless of the number of accounts active in that month. The second and third columns are the time-series maximum and minimum of the cross-sectional mean, showing the extreme extent of time-variation in cross-sectional average account behavior. The second set of three columns reports cross-sectional moments of time-series means calculated for each account over its active life, giving equal weight to each account for which the given characteristic can be measured in at least twelve months. Since the cross-sectional dimension of the dataset is much larger than the time-series dimension, we

\footnotetext{
${ }^{7}$ See the SEBI website, http://www.sebi.gov.in/mf/unithold.html.
} 
report the 10th percentile, median, and 90th percentile of the cross-sectional distribution.

For this table and all subsequent analysis, the data used represents a stratified random sample (described more fully in the next section) of individual accounts opened after January 2002. For accounts opened earlier, which represent about $14.4 \%$ of all individual accounts, we do not observe the full investing history, do not know when the account first invested in stocks, and do not observe the initial account characteristics. In our internet appendix, we show that our results are qualitatively unchanged when we perform our analyses with all individual accounts after making assumptions required to make use of the additional older accounts.

\section{Account size, number of stocks held, and location}

In the first panel of Table 2, we begin by reporting account sizes both in rupees (using Indian conventions for comma placement), and in US dollars, both corrected for inflation to a January 2012 basis. The cross-sectional average account size varies across months from under $\$ 5,000$ in 2004 to about $\$ 66,000$ in June 2008 , with a time-series mean of $\$ 24,771$. The median account size is however much smaller at $\$ 1,327$, and even the 90th percentile account size is only $\$ 10,815$, reflecting positive skewness in the distribution of account sizes. This positive skewness also explains the time-series variability of cross-sectional average account size, which is strongly influenced by the entry and exit of very large accounts. The large difference between mean and median account sizes implies that the weighting scheme used in summary statistics and regressions will have an important influence on the results. Given our focus on household finance questions, as opposed to the determination of Indian asset prices, we equally weight accounts in our empirical analysis as advocated by Campbell (2006).

The number of stocks held in each account is also positively skewed. The average number of stocks held across all accounts and time periods is almost 7 , but the median account holds only 3.4 stocks on average over its life. The 10 th percentile account holds 1 stock, while the 90th percentile account holds 14.3 stocks.

The next row shows that around $56 \%$ of individual accounts are associated with urban account addresses, $32 \%$ with rural addresses, and 12\% with semi-urban addresses. These 
relative shares do change somewhat over time. ${ }^{8}$

\section{Account performance}

The second panel of Table 2 looks at monthly account returns, calculated from beginningof-month stock positions and monthly returns on Indian stocks. These returns are those that an account will experience if it does not trade during a given month; in the language of Calvet et al. (2009a), it is a "passive return". It captures the properties of stocks held, but will not be a perfectly accurate measure of return for an account that trades within a month. ${ }^{9}$

The table shows that on average, individual accounts have slightly underperformed the Indian market (proxied by a value-weighted index that we have calculated ourselves). There is considerable variation over time in the cross-sectional average, with individual accounts underperforming in their worst months by as much as $4.8 \%$ or overperforming in their best months by as much as $10.2 \%$. This variation is consistent with the literature on institutional and individual performance in US data (e.g. Grinblatt and Titman 1993, Kovtunenko and Sosner 2004, Kaniel et al. 2008), and can be explained in part by style preferences of individual investors. There is also dramatic variation across investors in their time-series average performance, with the 10th percentile account underperforming by $1.75 \%$ per month and the 90 th percentile account outperforming by $1.52 \%$ per month.

\section{Underdiversification}

The next set of three rows examines account-level statistics that proxy for the investment mistakes described in the introduction. The idiosyncratic share of portfolio variance is calculated from estimates of each stock's beta and idiosyncratic risk, using a market model with the value-weighted universe of Indian stocks as the market portfolio, using a procedure very similar to that employed in Calvet et al. (2007). In order to reduce noise in estimated stock-level betas, however, we do not use realized stock-level betas but instead use fitted values from a panel regression whose explanatory variables include stock-level realized betas

\footnotetext{
${ }^{8}$ The internet appendix describes the method used to classify accounts into location-based categories.

${ }^{9}$ The internet appendix provides details on our procedures for calculating Indian stock returns. The appendix also shows that our results are robust to consideration of "active" returns from intra-month trading.
} 
(in monthly data over the past two years), realized betas on four portfolios of similar stocks (formed based on industry, and size, value, and momentum quintiles), and a dummy for stocks that are less than two years from their initial listing. To reduce noise in the estimate of idiosyncratic risk, we estimate idiosyncratic variance from a $\operatorname{GARCH}(1,1)$ model. ${ }^{10}$

The average idiosyncratic share is about $45 \%$ in both the time-series and cross-sectional moments, which is slightly lower than the median idiosyncratic share of $55 \%$ reported by Calvet et al. (2007), the difference probably resulting from our use of an Indian rather than a global market index. Once again there is considerable variation over time (from $25 \%$ to $55 \%$ ) and across accounts (from $24 \%$ at the 10 th percentile to $68 \%$ at the 90 th percentile). However, the idiosyncratic share of portfolio variance is not skewed to the same degree as the number of stocks held (reported in the top panel of the table), reflecting the convex declining relation between the number of stocks held in a portfolio and the portfolio's idiosyncratic risk.

\section{Turnover}

We measure turnover by averaging sales turnover and purchase turnover. Sales turnover equals the value of last month's holdings (at last month's prices) that were sold in the current month divided by the geometric average of the value of last month's holdings and the current month's holdings. This value is winsorized at $100 \%$. Purchase turnover equals the value of the current month's holdings (at current prices) that were bought in the current month, divided by the same denominator and also winsorized at 100\%. Our measure of turnover is not particularly high on average for Indian individual accounts. The time-series mean of the cross-sectional mean is $5.7 \%$ per month (or about $68 \%$ per year), and the cross-sectional median turnover is only $2.6 \%$ (or $31 \%$ per year). Turnover this low should not create large differences between the passive return we calculate for accounts and the true return that takes account of intra-month trading. Once again, however, there is important variation over time and particularly across accounts. The 10th percentile account has no turnover

\footnotetext{
${ }^{10}$ The GARCH model is first estimated for each stock, then is re-estimated with the GARCH coefficients constrained to equal the median such coefficient estimated across stocks. This approach deals with stocks for which the GARCH model does not converge or yields unstable out of sample estimates.
} 
at all (holding the same stocks throughout its active life), while the 90th percentile account has a turnover of $16.3 \%$ per month ( $196 \%$ per year).

Following Odean (1999), we have compared the returns on stocks sold by individual Indian investors to the returns on stocks bought by the same group of investors over the four months following the purchase or sale. In India, the former exceeds the latter by $2.41 \%$, which makes it more difficult to argue that trading by individuals is not economically harmful. By comparison, the difference Odean finds in US discount brokerage data is a much smaller $1.36 \%$. At a one year horizon following the purchase or sale, we find that stocks sold outperform stocks bought by $4.36 \%$ compared to $3.31 \%$ in Odean's data.

The disposition effect

We calculate the disposition effect using the log difference of the proportion of gains realized (PGR) and the proportion of losses realized (PLR), with these proportions both winsorized at $0.01 .^{11}$ This is a modification of the previous literature which often looks at the simple difference between PGR and PLR. By calculating a log difference, we eliminate any mechanical relation between the level of turnover and our measure of the disposition effect. PGR and PLR are measured within each month where the account executes a sale as follows: Gains and losses on each stock are determined relative to the cost basis of the position, which is observed whenever the position was established after the account was opened. In the remaining $35 \%$ of cases we use the median month-end price over the 12 months prior to NSDL registry as the cost basis. We only count sales where a position is fully sold, as partial sales could be driven by account re-balancing, but this convention makes little difference to the properties of the measure.

The disposition effect is important for Indian individual accounts. On average across months, the cross-sectional mean proportion of gains realized is 1.23 log points or $242 \%$ larger than the proportion of losses realized, while the median account has a PGR that is $1.35 \log$ points or $286 \%$ larger than its PLR. While both time-series and cross-sectional variation in the disposition effect are substantial, it is worth noting that over $90 \%$ of accounts in the

\footnotetext{
${ }^{11}$ Our results are robust to reasonable variation in this winsorization threshold.
} 
sample with 12 or more months with sales exhibit this effect.

In the internet appendix, we compare the disposition effect in our Indian data with US results reported by Odean (1998). Specifically, we plot the mean ratio of PGR and PLR aggregated across accounts by calendar month, a series that can be compared with Odean's numbers. The Indian disposition effect is considerably stronger on average than the US effect, and in both India and the US, the disposition effect is weaker towards the end of the tax year (calendar Q4 in the US, and calendar Q1 in India).

Style tilts

Table 2 also reports several measures of individual accounts' style tilts. We construct account-level betas with the Indian market by estimating stock-level betas as described earlier, and then value-weighting them within each account. The average beta is very slightly greater than one at 1.03 in both the time-series and cross-sectional moments. The cross-sectional mean betas have modest variation over time from 0.95 to 1.09 , and the crosssectional variation in the time-series average beta is also small.

In US data, individual investors overweight small stocks and institutional investors overweight large stocks (Falkenstein 1996, Gompers and Metrick 2001, Kovtunenko and Sosner 2004). We measure this tendency in our Indian dataset by calculating the value-weighted average inverse market-capitalization (i.e. "small") percentile of stocks held in individual accounts, relative to the value-weighted average market-capitalization percentile of stocks in the market index. We scale this by the difference in market-capitalization percentiles between market-capitalization-sorted portfolios constructed in the manner of Fama and French (1993). As a result, the reported time-series mean small tilt indicates that the average small (or inverse size) percentile of the individual investor is equal to the small percentile of a portfolio consisting of the market, a long position of $8.54 \%$ in the small-stock portfolio, and a short position of $-8.54 \%$ in the large-stock portfolio. The implied small tilt varies modestly over time, but never switches sign. The tilt is skewed across accounts: the 10th percentile account has a roughly a $6 \%$ large tilt while the 90 th percentile account has a $34 \%$ small tilt. Individual Indian investors also have a modest average tilt towards value stocks. Ranking stocks by their book-market ratio and calculating a value tilt in the same manner as we did 
for smallness, we find that the time-series mean value tilt is about $11 \%$. This value tilt varies over time and does switch sign, reaching around $-15 \%$ in the month that is most tilted towards growth. There are also very large differences across accounts in their tilt towards growth or value, with a spread of about $80 \%$ between the 10 th and 90 th percentiles of accounts. Finally, individual investors have a contrarian, or anti-momentum tilt. Calculating the momentum tilt using our standard methodology, we find that both the time-series mean and cross-sectional median momentum tilts are about $-8 \%$. This pattern is consistent with results reported for US data by Cohen et al. (2002), and with short-term effects of past returns on institutional equity purchases estimated by Campbell et al. (2009).

\section{Cross-sectional correlations of characteristics}

In the internet appendix we ask how the account characteristics described in Table 2 are correlated across accounts. We calculate cross-sectional correlations of account characteristics for each month, and then report the time-series mean of these correlations. To limit the influence of outliers, we winsorize account-level stock returns at the 1st and 99th percentiles, and winsorize account value below at 10,000 rupees (approximately $\$ 200$ ). There are a number of intriguing patterns in these correlations. Older accounts tend to be larger, and account age is negatively correlated with all three of our investment behavior proxies - an effect we explore in detail in the next section. Among investment behaviors, turnover also has a 0.33 correlation with the idiosyncratic share of portfolio variance, implying that underdiversified accounts tend to trade more. All the investment behaviors are positively correlated with accounts' market betas and small tilts, implying that accounts holding high-beta and small-cap stocks tend to be less diversified, trade more, and have a stronger disposition effect. The log of account value correlates negatively with beta, small, and value, and positively with momentum tilts. This implies that larger individual accounts look more like institutional accounts in that they prefer lower-beta stocks, growth stocks, large stocks, and recent strong performers. Finally, there is a strong correlation of 0.47 between the small and value tilts, implying that individuals who hold value stocks also tend to hold small stocks. This effect is somewhat mechanical given the correlation of these characteristics in the Indian universe. 


\section{The Effects of Age and Feedback: Methodology}

In this section we describe our approach to understanding how Indian investors learn. We consider two potential sources of learning. The first is the amount of time spent by an investor in the market, which we proxy by the time elapsed since the investor began to hold stocks in an account. The second is the set of specific experiences that each investor has had in the market. Our econometric specifications identify the first of these sources as an age effect in the panel of investors, and the second using the fact that variation in portfolio holdings across investors and time generates variation in their "experienced returns." We use these specifications to explain and forecast the evolution of investors' behaviors, style demands, and overall performance.

Our empirical specifications are constructed to capture variation in behaviors, style demands, and performance arising from age and feedback. However, to ensure that we correctly identify these effects, we need to control for the effect of broader temporal fluctuations in the Indian market, as well as the possibility that individuals differ in their inherent preferences, ability, or sophistication.

To begin, consider a specification which provides for estimation of all these sources of potential variation in behavior, style tilts, and performance, represented generically as an outcome $Y_{i t}$ below:

$$
Y_{i t}=s_{i}+\delta_{t}+\beta A_{i t}+\gamma X_{i t}+\varepsilon_{i t}
$$

where $s_{i}$ is an investor fixed effect, $\delta_{t}$ represents an unobserved time fixed effect, $A_{i t}$ is a measure of the age of account $i$ at time $t$, and $X_{i t}$ is a predictor variable such as the feedback experienced by investor $i$ at time $t$. In the case where $Y_{i t}$ measures investment performance, we might think of $s_{i}$ as capturing the inherent sophistication or investment ability of investor $i$.

We can re-write equation (1) in cross-sectionally demeaned form as:

$$
Y_{i t}-Y_{t}=\left(s_{i}-s_{t}\right)+\beta\left(A_{i t}-A_{t}\right)+\gamma\left(X_{i t}-X_{t}\right)+\varepsilon_{i t}
$$


where $s_{t}$ is the cross-sectional average fixed effect of investors in the market at time $t$. As investors enter and exit the market, $s_{t}$ could vary over time.

The fatal drawback of equations (1) and (2) is that they are not identified on account of perfect collinearity. This is the usual problem with any specification containing a linear transformation of unrestricted age effects, unrestricted cohort or individual effects, and unrestricted time effects (Ameriks and Zeldes 2004, Guiso and Sodini 2013).

To estimate the objects of interest $(\beta$ and $\gamma)$, we therefore apply restrictions on $s_{t}$ in equation (2). The simplest such restriction that we employ is that $s_{t}=0$, which in the case of a performance regression implies that the average inherent sophistication of investors in the market does not change with time. Applying this restriction, we arrive at our baseline specification:

$$
Y_{i t}-Y_{t}=s_{i}+\beta\left(A_{i t}-A_{t}\right)+\gamma\left(X_{i t}-X_{t}\right)+\varepsilon_{i t}
$$

Our baseline specification is vulnerable to a few econometric difficulties. First, it is possible that the average inherent sophistication of Indian investors has been changing over time as market participation expands. To address this possibility, we model these changes in the internet appendix using the cross-sectional average of a set of investor attributes, i.e., by estimating:

$$
Y_{i t}-Y_{t}=\left(s_{i}-\alpha C_{t}\right)+\beta\left(A_{i t}-A_{t}\right)+\gamma\left(X_{i t}-X_{t}\right)+\varepsilon_{i t}
$$

where $C_{t}$ includes the cross-sectional average of investor initial log account value and investor initial number of equity positions, as well as the income and literacy rates of the states in which investors are located, and the share of the investor population residing in rural and urban areas. Put differently, specification (4) simply attempts to fit cross-sectional average sophistication with the set $C_{t}$ of cross-sectional average investor attributes. We find that the majority of our results are unaffected by the introduction of these variables $C_{t}$, though their introduction weakens identification of age effects.

Second, panel estimation with fixed effects can deliver biased estimates when explanatory 
variables are not strictly exogenous. Intuitively, if the time dimension of the panel is short, and if high values of $Y_{i}$ early in the sample predict high future values of $X_{i}$, then relative to its sample mean $Y_{i}$ must be low later in the sample. As a result, $Y_{i}$ will spuriously appear to be negatively predicted by $X_{i}$. This is a particular problem if we use account size as an explanatory variable to predict returns, since account size is mechanically driven in part by past returns. Similar issues may arise when we use investment behaviors or style tilts as explanatory variables, if their prevalence is behaviorally influenced by past returns.

Even the use of account age as an explanatory variable may suffer from this problem if the disposition effect - the tendency of investors to sell gains rather than losses - leads to disproportionate exit of investors who have been lucky, as reported by Calvet et al. (2009a). In this case, the surviving, experienced investors may disproportionately be investors who had poor returns when they were novices. In the presence of investor fixed effects, this can produce an upward bias in the estimated effect of account age on portfolio returns. This bias can also exist in age effects in our behavior and style regressions to the extent that behaviors are also influenced by returns.

Fortunately violations of strict exogeneity are less serious in our application than in many panel estimation exercises because our panel has a relatively long time dimension, and the outcomes we study are generally not strong predictors of subsequent control variables. Furthermore, in the internet appendix we respond to the problem by estimating an alternative specification:

$$
Y_{i t}-Y_{t}=\theta\left(C_{i}-C_{t}\right)+\beta\left(A_{i t}-A_{t}\right)+\gamma\left(X_{i t}-X_{t}\right)+\varepsilon_{i t}
$$

This specification restricts the individual fixed effects used in (3), modeling them using the same set of investor attributes $C$ described above. By eliminating the use of sample mean $Y_{i}$ to estimate fixed effects, the specification protects against the bias discussed above. The appendix shows that our inferences about the impact of variables (such as feedback variables) for which we might be concerned about bias arising from violations of strict exogeneity are unaffected in this new specification.

With regard to the specific issue of luck-driven account exit, in the internet appendix we 
model the relationship of account exit and investor behaviors to past returns and use this to simulate survival bias in account age effects using our primary specification. We find that the account exit rate is too modest, and too weakly related to past returns for our inferences to be affected significantly.

A few notes on estimation. First, we focus primarily on a flexible piecewise linear form for the account age effect. Second, all our regressions, except account returns, include log account size as a control variable. Third, when predicting investment behaviors we also include lagged behavior, $Y_{i t-1}$, as a regressor. The inclusion of a lagged outcome variable makes the model one in which there is partial adjustment to a target which depends on account age and the investor's feedback. Since changes in account age are permanent, we report the impact of account age on the target level of behavior. Feedback is almost entirely transitory, so we report the impulse response function, that is, the effect of lagged feedback on behavior taking into account the endogenous response of lagged behavior and its effect on current behavior.

We consider two sources of feedback in our empirical estimation. The first, which we term "account performance feedback" is the historical total outperformance of the investor relative to the market. The coefficients on account performance feedback capture the effects on the outcome variables of interest (behavior and style demands) of the investor performing relatively well or relatively poorly over a period of time. The second is "behavior-specific" or "style-specific" feedback. We measure this source of feedback using historical experienced returns attributable specifically to the past behavior or style tilt of the investor which we seek to explain. For example, when forecasting investor turnover, the turnover-specific feedback is measured as the increase in returns due to trading activity. This is computed as the difference between actual returns in the current month and the returns that would have obtained if no trades had been made in the past three months.

Our regressions are estimated on a stratified random sample, drawing 5,000 individual accounts from each Indian state with more than 5,000 accounts, and all accounts from states with fewer than 5,000 accounts. The internet appendix shows that, as expected, state participation rates are highly correlated with per-capita state income. Our return 
regressions are estimated using about 4.2 million account months of data spanning January 2004 through January 2012, and our regressions of account behaviors and style tilts use somewhat fewer observations, as these measures cannot be defined for as many account months.

We estimate panel regressions applying equal weight to each cross-section, and within each cross-section, we use weights to account for the sampling strategy. Standard errors are computed by bootstrapping months of data, to account for any possible contemporaneous correlation of the residuals. This estimation methodology is in the spirit of the well-known Fama-Macbeth regression method (since it gives each time period equal weights, and assumes errors are cross-sectionally correlated within each period but uncorrelated across periods), although ours differs in its inclusion of account fixed effects.

These panel regressions are reported in Tables 3 (investment behaviors) and 4 (net demands for styles, defined in section 5.1). Table 3 reports the coefficients on log account value and lagged behavior, showing that large accounts are better diversified, have higher turnover, and lower disposition bias, and that underdiversification is highly persistent, turnover less so, and disposition bias is actually negatively serially correlated. Table 4 reports the coefficients on log account value and lagged style tilts, showing that large accounts have a greater tendency to accumulate small stocks and growth stocks. For example, for each log unit increase in account value, the increase in net demand for small and growth stocks has equivalent impact on portfolio tilts as a monthly shift of $0.077 \%$ of the portfolio from large to small stocks, and $0.117 \%$ from value to growth stocks. The table also shows that all net style demands are negatively related to lagged style tilts, capturing a tendency for investors to move their portfolios towards the average style characteristics of stocks in the Indian market.

The age and feedback effects in the regressions of Tables 3 and 4 are the main focus of this paper and are discussed in the following sections. Since these effects are modeled in a relatively unrestricted way, it is easier to interpret them in graphical form. 


\section{Age and Feedback Effects on Behavior}

\subsection{How behavior changes with age}

We first ask whether our three proxies for investment behaviors change with the age of the account. In our specifications, we predict the idiosyncratic share of portfolio variance, turnover, and disposition bias measured by the log ratio of PGR to PLR using specification (3), allowing for a piecewise linear age effect. Figure 1 shows these age effects; this form of presentation carries through our analysis of style tilts and performance. In the plot, the solid line represents the point estimate from the regression, and the surrounding dotted lines encompass the $95 \%$ confidence interval. We scale behaviors by the time-series average of their cross-sectional means reported in Table 2.

The age effects documented in Figure 1 are large in economic magnitude. Over the course of five years, monthly turnover declines by a statistically significant $75 \%$ of the mean, with this number becoming an even larger $98 \%$ for an eight-year old account relative to a novice account. The disposition bias declines by $42 \%$ for a five-year account relative to a novice, although the internet appendix shows that much of this effect may be attributable to the fact that early cohorts appear more sophisticated along the dimension of the disposition bias. In contrast, the idiosyncratic share of portfolio variance changes little with age. This may not be surprising when considering the results of Ivkovic et al. (2008), who suggest that underdiversification may in some cases result from stock-specific information possessed by sophisticated investors - they find that individual trader performance improves as the number of stock holdings decrease, holding other determinants of performance constant.

\subsection{How behavior changes with feedback}

Since two of our behavior measures vary strongly with account age, it is plausible that behavior may also be affected not only by the fact of investing, but also by the experiences that investors have in the market. Figure 2 shows the impacts of feedback on the three behaviors that we consider (in rows), with the two columns showing, respectively, the impacts of past 
total account performance relative to the market, and past behavior-specific feedback.

In the first row, we consider the impact of the outperformance of the account relative to the market on the future idiosyncratic share of portfolio variance. The figure shows that account outperformance leads investors to make larger idiosyncratic bets, especially over the first quarter following an increase in performance. The estimated coefficient implies that the idiosyncratic share of portfolio variance becomes about $22 \%$ higher than the mean idiosyncratic share for an account that has recently outperformed the market by $100 \%$. This may be because past outperformance encourages investors to assess their investing skills more optimistically, in turn leading them to increase their idiosyncratic bets. ${ }^{12}$

The second row of Figure 2 shows the ability of feedback to predict turnover. Again, outperformance of the account relative to the market appears to have a significant effect on turnover, with a rise of over $70 \%$ relative to mean turnover following an account return of $100 \%$ relative to the market. The effect is slightly longer-lived than the impact on the idiosyncratic variance share, although it continues to show a relatively rapid decline following the first quarter after the elevated account outperformance.

In the same row, the second column shows the impact of the increase in returns due to trades, a measure of an account's past trading success. Turnover-specific feedback from a given month is the difference between actual returns in that month and the returns that would have obtained if the investor had not traded in the previous three months. This variable strongly predicts turnover, implying that trading profits strengthen the tendency to trade stocks frequently. ${ }^{13}$ Specifically, a return of $100 \%$ from recent trading initially increases turnover by over $100 \%$ of its cross-sectional mean. Even after several years, the effect remains statistically significant and economically important at about $30 \%$ of the cross-sectional mean.

\footnotetext{
${ }^{12}$ Note that the presence of the lagged idiosyncratic variance share in the regression controls for any mechanical impact (given less than complete rebalancing within the month) of the return to an undiversified account on the end-of-month idiosyncratic variance share of the account. That is, we measure account return during the month leading up to the measurement date for the lagged idiosyncratic variance share, not the month following that measurement date. In this way we guarantee that the effects we estimate are behavioral and do not result mechanically from imperfect rebalancing.

${ }^{13}$ This result is consistent with the findings of Linnainmaa (2011), who employs information on a set of high-frequency traders from Finland.
} 
It should be noted that the effects of recent account performance and trading profits on turnover may result in part from the disposition effect. If recent trading is profitable, then an account has tended to purchase winners, and these are more likely to be sold if the investor has a disposition bias. Such sales, and subsequent purchases of replacement stocks, increase turnover. However, the stronger response of turnover to trading profits than to account performance, and the persistence of the response to trading profits, suggest that the disposition effect is not the only factor driving turnover.

Finally, in the third row, we predict disposition bias. The figure in the first column of this row shows that high account outperformance relative to the market substantially increases the short-term tendency to sell winners rather than losers. The second column uses a more specific measure of feedback which captures the impact of disposition-bias-induced selling on account returns. We calculate excess returns relative to the market index on stocks that each account sold, during the three month period following each sale, and compare the excess returns to losers sold relative to winners sold, weighting by the value of each sale. This feedback measure could be positive if the account holds mean-reverting stocks, or negative if the account holds stocks that display momentum. This variable predicts future disposition bias with the expected positive sign, but the effect is not statistically significant. ${ }^{14}$

Figure 3 illustrates the relative importance of account age and investment experience in predicting each of our three investment behaviors. For all accounts that opened in December 2003, the figure shows the predicted behaviors from January 2004 through the end of the sample, using all the predictor variables except account value from our specifications. The figure illustrates the median and the 10th and 90th percentiles of predicted behaviors. In both the disposition effect and turnover plots, the dominant influence of the age effect is clearly visible in the figure, suggesting that Indian retail investors are indeed "getting better" overall. The spread in predicted behaviors across accounts is meaningful for both idiosyncratic variance share and turnover, emphasizing that there is substantial variation in the extent to which investors are "feeling better" - and that feeling worse, especially early

\footnotetext{
${ }^{14}$ Consistent with this result, Ranguelova (2001) finds that disposition bias is attenuated among investors who hold small US stocks with greater momentum in their returns.
} 
on, may indeed be helpful in the longer run. The internet appendix decomposes the spread into parts separately attributed to variation in account performance and behavior-specific feedback.

One might think that feedback effects vary with account age, implying a nonlinear interaction between the age and feedback variables in our regressions. We have explored regressions of this sort but find few statistically significant results and no consistent patterns in the interaction coefficients (see our internet appendix).

This section has provided evidence for reinforcement learning among Indian equity investors. Our interpretation might be challenged if there is reverse causality, for example if skilled traders generate trading profits and continue to trade frequently in the future, or if certain investors specialize in holding mean-reverting stocks for which realizing gains and holding losses is a systematically profitable strategy. The presence of account-level fixed effects in our specifications should significantly reduce concerns on this score, as the investor's average skill at trading should be absorbed by these account-level effects. In addition, we will show during our analysis of the impacts of behavior on performance that both turnover and the disposition bias are associated with lower account returns, not higher returns as reverse causality would require. We now turn to the impacts of age and feedback on another important dimension of investment behavior, namely, investors' demands for particular styles of stock.

\section{Age and Feedback Effects on Style Demands}

\subsection{How net style demands change with age}

We focus on measures of style demand and supply. Style demand is defined as the crosssectionally demeaned percentile of the portfolio of stocks bought by the investor multiplied by the purchase turnover of that investor. Thus, demand for value can be high when an investor buys a sizable amount of stocks with a modest value tilt or a modest amount of stocks with a sizable value tilt. As with our measures of style tilt in Table 2, we scale style 
demand by the difference in style percentiles between style-sorted portfolios constructed in the manner of Fama and French (1993). Then, value demand of $1 \%$ is equivalent to the impact of reducing purchases of the Fama-French growth portfolio by an amount equal to $1 \%$ of the investor's equity holdings, and reallocating these purchases to the Fama-French value portfolio. Style supply is defined similarly, but for the investor's sales. We are especially interested in net style demand, which is the difference between style demand and style supply. The internet appendix provides separate results for style demand and supply.

It is important to understand that net style demand does not translate directly into a change in the style characteristics of an investor's portfolio. Because the style characteristics of any individual stock tend to regress towards the mean (with value stocks becoming more expensive relative to book value and growth stocks becoming cheaper, for example), a styletilted portfolio requires some net style demand just to maintain its current style tilt. This effect is more important for large style tilts, so for example an investor who wishes to maintain an extreme value tilt must continually sell those stocks in the portfolio that have lost their extreme value characteristics, and replace them with the cheapest stocks available in the market. While for some purposes one might be interested in the dynamics of portfolio characteristics (studied by Calvet et al. 2009a, for example), net style demand directly measures investors' trading behavior and hence indirectly measures the price pressure that investors create on style portfolios.

The three plots of Figure 4 show how net style demand varies with age for three different style dimensions, namely size, value, and momentum. The top panel shows that the net small demand of an investor with eight years of experience exceeds that of a new investor by about $0.45 \%$ per month. The middle panel indicates that net value demand increases even more with account age, increasing by a total of about $1.8 \%$ over the first eight years. Our finding here is consistent with the results reported by Betermier et al. (2013) for older investors in Sweden, although it is important to keep in mind that Betermier et al. work with the age of underlying investors, not our measure of account age. As discussed further in the next section, these trends in net style demand contribute to the effect of experience on account performance. 
The bottom panel of Figure 4 demonstrates a modest U-shaped effect of account age on the accumulation of momentum stocks - one cannot reject the hypothesis that eight-yearold accounts have momentum tilts that are comparable to those of novice investors, with a minimum rate of accumulation of winners at the five-year age mark. This may result from novices entering the market by purchasing well known stocks that have recently appreciated, then moving to a more neutral investing style, and then perhaps appreciating the evidence for momentum profits when they become extremely experienced.

The internet appendix shows that these results are driven by the effects of account age on both style demand and style supply. However, the increasing net demand for small stocks is driven more by intensifying purchases of small stocks, whereas the increasing net demand for value stocks is primarily due to a reduction in the tendency to sell value stocks.

\subsection{How net style demands change with feedback}

Figure 5 illustrates the impacts of an account's overall market-relative performance on the investor's net style demands. The left column of the figure shows the impact on net style demands as a function of the time elapsed since the the outperformance occurred. The right column of the figure integrates these responses to show the cumulative impacts of performance on the investor's trading behavior. The top panel of the figure shows the impact on net small demand, the second panel shows the impact on net value demand, and the third panel shows the impact on net momentum demand.

Impacts of account outperformance are substantial, persistent, and highly statistically significant, with outperformance predicting higher net demands for large, growth, and momentum stocks. Even four years after a 100\% outperformance by an account, net demand for small stocks is about 25 basis points per month lower, net demand for value stocks is about $1 \%$ per month lower, and net demand for momentum stocks is about 40 basis points per month higher. The cumulative effect on net style demand at the four-year mark is over $10 \%$ lower for small stocks, over $60 \%$ lower for value stocks, and over $25 \%$ higher for momentum stocks. 
The internet appendix shows that the positive effect of account outperformance on net style demand for large, growth, and momentum stocks comes mostly from reduced investor sales of these styles. One possible interpretation is that large, growth, and momentum stocks have similar characteristics to the best performing stocks among investors' current and recent holdings. The disposition effect implies that investors tend to sell their specific winners, but when their overall account performance has been good this tendency may be weaker, and they may also seek to replace these winners with other stocks that have similar characteristics at the date of sale. It is also likely that outperformance increases overconfidence, as suggested by Daniel, Hirshleifer, and Subrahmanyam (1998), Gervais and Odean (2001), Statman, Thorley, and Vorkink (2006), and Kruger (2013). However, while overconfidence might explain a preference for growth stocks it is not clear that it should generate tilts towards large-cap or momentum stocks.

Figure 6 is constructed in the same way as Figure 5, but shows the impact of stylespecific feedback on investors' net style demands. This style-specific feedback is constructed by taking the total returns on the sub-portfolio of stocks held by the investor that are ranked above the cross-sectional average of all stocks in the same period on the given style (i.e., size, value, and momentum) minus the total returns on the sub-portfolio of stocks held by the investor ranked below average in the given style. In cases in which the investor does not own stocks ranked above or below the average for a given style, value-weighted market returns are substituted for the type of stocks that the investor does not own (e.g. growth, if an investor holds only value stocks).

The plots show that there are two impacts of style-specific feedback. The first is a more precisely estimated short-term effect, in which the investor decumulates the style that has outperformed. The internet appendix shows that this short-term effect is due to a spike in supply of the outperforming style, suggesting this is a manifestation of the disposition effect. However, for all three of the styles, the less precisely estimated but far longer-lived effect is a tendency to continue to accumulate styles in which the investor has experienced positive returns. This "style chasing" behavior is consistent with the theoretical model of Barberis and Shleifer (2003). For all three cases, the cumulative net demand is positive, 
indicating that style chasing ultimately more than offsets the initial decumulation. However, this positive cumulative net effect is statistically significant only for value. The maximum effect at 4 years implies that over this horizon, a 100\% outperformance of value stocks induces investors to adjust their portfolios by an amount equivalent to a shift of about $3 \%$ of their portfolios from the Fama-French growth portfolio to the Fama-French value portfolio. While this effect is identified from cross-sectional variation in experienced returns to value, the internet appendix calculates the implied response of aggregate individualinvestor demand to an aggregate outperformance of value stocks relative to growth stocks of $20 \%$. After taking account of the effect on aggregate individual-investor performance, which also influences style demand, such a shock implies a four-year adjustment of $0.8 \%$ of the aggregate individual-investor portfolio from growth to value stocks.

Figure 7 illustrates the relative importance of account age and investment experience in predicting each of the three net style demands. For all accounts that opened in December 2003, the left hand side plots show the predicted changes to net style demands from January 2004 through the end of the sample, using all the predictor variables except account value from our specifications. For the right hand side plots, these changes to net style demand are cumulated over time, with the benchmark implicitly being the cumulative net style demands of a perpetual novice investor. All plots show the median, 10th, and 90th percentiles of these predictions. In both the size and value plots, the dominant influence of the age effect on net demand is visible, which in a market such as India with positive size and value premiums, suggests that Indian retail investors are "getting better" with overall experience in the market. However, the spread in predicted behaviors across accounts generated by differential feedback, or "feeling better", is meaningful in all three cases.

As in the case of investment behaviors, we have considered interaction effects between age and feedback, but have not found statistically significant or economically meaningful interactions. To save space we report these specifications only in the internet appendix. 


\section{Implications for Performance}

In the previous sections we have shown that both account age and investment experiences strongly affect behaviors and net style demands. How do these sources of learning feed into overall performance? In this section we analyze the impacts of age, behaviors, and style tilts on investor performance.

Performance is inherently difficult to measure, because account returns are subject both to considerable idiosyncratic volatility and to common shocks resulting from our measured style tilts and other systematic tilts. Accordingly we look at performance using three different approaches. First we measure performance directly at the account level; then we analyze the returns on portfolios of stocks held by novice and experienced investors; and finally we predict the returns on individual Indian stocks using the characteristics of the investor base as well as characteristics of the stocks and companies themselves.

\subsection{Determinants of account performance}

The top plot of Figure 8 shows the impact of age on account performance, estimated from a piecewise linear model. While the reported age effects have substantial economic magnitudes (roughly 100 basis points a month higher for an eight year old investor relative to a novice), they are imprecisely estimated and only barely significant at the five percent level at seven years. The internet appendix reports more comprehensive results, showing that the age effect remains economically meaningful but statistically insignificant when it is restricted to be linear. When we add measures of investor behavior and style tilts as explanatory variables, we find that changes in these behaviors with experience account for about onethird of the age effect on returns.

It is important to note that these performance results do not account for transactions costs. In India one-way levies and fees (primarily in the form of a securities transaction tax) of about 20 basis points plus brokerage fees of around 10-30 basis points result in an estimate of direct trading costs of 30 to 50 basis points each way. The predicted difference in monthly (two-way) turnover between the oldest and newest quintile of accounts is just under 
$5 \%$. Combining these facts leads to the estimate that increased turnover reduces after-cost returns of the newest quintile of accounts relative to the oldest by about 3 to 5 basis points per month, strengthening the return to experience illustrated in Figure 8.

\subsection{Aggregated novice- and experienced-investor portfolios}

We now analyze the returns to various portfolios formed on the basis of stockholder account age. There is no equivalent of the fixed effects we have used in our study of individual accounts, so we do not attempt to distinguish stocks that are preferred by older accounts because of these accounts' constant characteristics from stocks that are increasingly preferred by accounts as they grow older.

We first form representative stock portfolios for individual investors sorted by accountage quintile. The representative older individual account has a stratified-sample-weighted average of the portfolio weights of accounts in the top quintile of account age, while the representative novice account is formed in the same way from accounts in the bottom quintile of account age. The bottom plot of Figure 8 illustrates the cumulative excess returns (relative to the Indian short rate) to the experienced-investor and novice-investor portfolios, along with the overall excess return of the Indian equity market, over the period January 2004-January 2012. By the end of this period the cumulative excess return on the experienced-investor portfolio was $89 \%$, while the cumulative excess return on the Indian market index was $79 \%$, and the cumulative excess return on the novice-investor portfolio was only $10 \%$. In the internet appendix, we also plot an exponentially weighted moving average of the difference in returns on the experienced and novice portfolios. This shows that the novice portfolio outperformed only in 2004, late 2007, and during the surge in stock prices in the spring of 2009.

We next form a zero-cost portfolio that goes long the representative older account and short the representative novice account. The first column of Table 5 reports results for this portfolio. The second and third columns decompose it into long-short portfolios formed between the older and average (i.e. middle-quintile) representative investor and between the 
average and novice representative investor.

In the first column of Table 5, we regress the portfolio weights in the older minus novice zero-cost portfolio onto a vector of stock characteristics, to see what characteristics are preferred or avoided by older investors relative to novice investors. The second and third columns of the table do the same for the older minus average and average minus novice portfolios respectively. In the bottom of the table, we show how the returns on the zerocost portfolios can be attributed into unconditional and timing effects related to either stock characteristic tilts or a residual that we call "selectivity" following Wermers (2000). This decomposition is described in our internet appendix.

The table shows that relative to novice investors, the most experienced Indian investors tilt their portfolios towards small stocks, value stocks, stocks with low turnover, stocks without large beneficial ownership, and stocks held by institutions. Experienced investors also avoid large, attention-grabbing initial public offerings. This is unsurprising considering that such IPOs are one of the main routes to initial investor participation in the Indian stock market.

In terms of their contribution to performance, the stock characteristics of older investors explain only 9 basis points out of a total outperformance relative to novice investors of 38 basis points per month. The remainder is not explained by characteristic timing, which makes an insignificant but negative contribution of 10 basis points. The performance differential is attributable mainly to stock timing effects (27 basis points) and non-characteristic related stock selection (13 basis points). Most of these differences are preserved when looking at the difference between average aged and novice accounts, implying that the initial mistakes made by inexperienced investors ("rookie mistakes") contribute to the performance differential between experienced and novice accounts.

In the first column of Table 6 we evaluate the older minus novice zero-cost portfolio in a different way, by regressing its return on six factors commonly used in the asset pricing literature: the market return, small minus big (SMB) return, value minus growth (HML) return, momentum (UMD) return, and factor portfolios capturing short-term reversals and illiquidity as measured by turnover. We find that the portfolio has a negative loading on HML, 
despite its slight tilt towards value characteristics, and has a significantly positive six-factor alpha. This result implies that experienced investors add value not by taking compensated factor exposures, but by finding outperforming stocks whose factor exposures are generally poorly compensated. To the extent that this is the case, the results of Coval et al. (2005) that following high-performing individual investors' trades generates high abnormal returns should also apply to a strategy of emulating experienced investors' equity holdings.

The remaining columns of Table 6 repeat this exercise using zero-cost portfolios that go long stocks held by investors with high levels of behaviors or style tilts, and short stocks held by investors with unusually low levels of these behaviors or style tilts. It appears that underdiversified investors hold stocks with compensated factor exposures, but do not add value relative to the six-factor model, while high-turnover investors have similar factor exposures to underdiversified investors but have a significantly negative alpha relative to the model.

\subsection{Stock returns and the investor base}

Finally, we change our focus from the performance of individual accounts to the performance of the stocks they hold, as predicted by the investor base of those stocks. This is analogous to the recent literature on the performance of mutual funds' stock picks, as opposed to the overall performance of the funds themselves (Wermers 2000, Cohen et al. 2010).

Table 7 uses Fama-Macbeth regressions to predict the returns of Indian stocks with at least 10 individual investors in our sample of individual accounts. Column 1 shows that the average age of the accounts that hold a stock predicts the return to that stock, consistent with the account-level results in Figure 8. Column 2 adds information on the behavior of the investor base - the average idiosyncratic share of portfolio variance of the stock's investors, the turnover of these portfolios, and the disposition bias of the stock's investors - as well as the style tilts of the investor base. The age effect, though somewhat diminished, remains significant, and we find that an investor base with high turnover predicts lower returns.

Column 3 adds a standard set of stock characteristics to the regression. The book-market 
ratio and momentum enter positively, and stock turnover enters negatively, consistent with evidence from developed markets. The effect of account age in the investor base is now much weaker, but stocks with underdiversified investors have lower average returns (significant at the $5 \%$ level), and stocks with disposition-biased investors have lower average returns. The effect of a high-turnover investor base remains negative, but declines in magnitude because it is correlated with turnover in the stock itself. Finally, we see that while large stocks have lower returns, stocks held by investors who favor large stocks - who may generally be larger, more sophisticated investors - tend to have higher returns.

The institutional ownership of stocks is included in Table 7 to address one possible concern about our finding of a positive age effect. Since institutional investors have gained market share over our sample period, stocks favored by such investors may rise in price just because they control more capital over time (Gompers and Metrick 2001). If older individual accounts are more like institutions, and hold similar stocks, this transitional effect may benefit long-established individual investors as well as institutions. However, in Table 7, the coefficient on institutional ownership is only weakly positive.

\section{Conclusion}

In this paper we have studied the investment strategies and performance of individual investors in Indian equities over the period from 2004 to 2012. We have measured the feedback investors receive from the returns on their equity holdings. Because these holdings are imperfectly diversified, we can use cross-sectional variation in feedback to help identify investor responses. Our results can be summarized in three main categories.

First, we find that both years of investment experience and feedback from overall investment performance are important drivers of investment behavior and style tilts. Turnover, disposition bias, and the propensity to invest in large growth stocks all decline with experience. However, strong investment performance relative to the aggregate market reduces diversification, increases turnover, and pushes investors towards large growth stocks. It appears that Indian investors typically develop investment skill over time, decreasing be- 
haviors and style tilts that are generally thought to reduce performance. Good investment performance early on, however, encourages what we might characterize as "bad" investment behavior through a reinforcement learning effect.

Second, we find evidence for narrower feedback effects that are driven not by overall investment performance, but by the experienced returns to specific investment behaviors and style tilts. Returns to recent trading activity encourage turnover, and this effect is highly persistent. Returns to style tilts within investors' portfolios, which vary idiosyncratically with the particular style stocks held, have short-term negative effects on net style demandprobably a manifestation of the disposition effect, as investors sell winning positions - but longer-term persistent positive effects that are consistent with theories of "style chasing". In the case of value, the cumulative effect is positive and statistically significant over a 2-4 year time horizon.

Third, we find that the Indian market rewards investment skill among individual investors. Experienced accounts tend to outperform novice accounts, although this effect is imprecisely estimated. Portfolios formed by aggregating experienced-investor holdings outperform portfolios of novice-investor holdings, and the characteristics of the investor base for Indian stocks, particularly investor experience and turnover, predict the returns on these stocks. The turnover of the investor base remains statistically significant even when controlling for the turnover and other characteristics of the stocks themselves.

These findings should be of interest beyond the particular Indian context in which we have obtained them. India is a natural laboratory in which to study investor learning, given the rapid development of its financial system and the availability of high-quality data on directly held equity portfolios, which represent the great majority of Indian equity investments. However the effects of experience and feedback on investor behavior and the rewards to investment skill documented in this paper are directionally consistent with fragmentary evidence from other countries, and are likely to reflect general patterns of investor behavior and stock price formation. Matching such patterns is an important challenge for future theoretical work in household finance and asset pricing. 


\section{References}

Agarwal, Sumit, Souphala Chomsisengphet, Chunlin Liu, and Nicholas S. Souleles, 2006, Do consumers choose the right credit contracts?, unpublished paper, available online at http://papers.ssrn.com/sol3/papers.cfm?abstract_id=843826.

Agarwal, Sumit, John C. Driscoll, Xavier Gabaix, and David Laibson, 2008, Learning in the credit card market, NBER Working Paper 13822.

Ameriks, John, and Stephen Zeldes, 2004, How do household portfolio shares vary with age?, unpublished paper, Columbia University.

Badrinath, S., and Wilbur Lewellen, 1991, Evidence on tax-motivated securities trading behavior, Journal of Finance 46, 369-382.

Barber, Brad M., and Terrance Odean, 2000, Trading is hazardous to your wealth: The common stock investment performance of individual investors, Journal of Finance 55, 773-806.

Barber, Brad M., and Terrance Odean, 2001, Boys will be boys: Gender, overconfidence, and common stock investment, Quarterly Journal of Economics, 116, 261-292.

Barber, Brad M., and Terrance Odean, 2002, Online investors: Do the slow die first? Review of Financial Studies, 15, 455-487.

Barber, Brad M., and Terrance Odean, 2008, All that glitters: The effect of attention and news on the buying behavior of individual and institutional investors, Review of Financial Studies, 21, 785-818.

Barber, Brad M., Yi-Tsung Lee, Yu-Jane Liu, and Terrance Odean, 2009, Just how much do individual investors lose by trading?, Review of Financial Studies 22, 609-632.

Barberis, Nicholas and Andrei Shleifer, 2000, Style investing, Journal of Financial Economics 68, 161-199. 
Betermier, Sebastien, Laurent Calvet, and Paolo Sodini, 2013, Who are the value and growth investors?, unpublished paper, McGill University, HEC Paris, and Stockholm School of Economics.

Blume, Marshall, and Irwin Friend, 1975, The asset structure of individual portfolios and some implications for utility functions, Journal of Finance 30, 585-603.

Calvet, Laurent, John Y. Campbell, and Paolo Sodini, 2007, Down or out: Assessing the welfare costs of household investment mistakes, Journal of Political Economy 115, $707-747$.

Calvet, Laurent, John Y. Campbell, and Paolo Sodini, 2009a, Fight or flight? Portfolio rebalancing by individual investors, Quarterly Journal of Economics 124, 301-348.

Calvet, Laurent, John Y. Campbell, and Paolo Sodini, 2009b, Measuring the financial sophistication of households, American Economic Review Papers and Proceedings 99, 393-398.

Campbell, John Y., 2006, Household finance, Journal of Finance 61, 1553-1604.

Campbell, John Y., Tarun Ramadorai, and Benjamin Ranish, 2014, Online appendix to Getting Better or Feeling Better? How Equity Investors Respond to Investment Experience, available online at scholar.harvard.edu/campbell.

Campbell, John Y., Tarun Ramadorai, and Allie Schwartz, 2009, Caught on tape: Institutional trading, stock returns, and earnings announcements, Journal of Financial Economics 92, 66-91.

Campbell, John Y. and Luis M. Viceira, 2002, Strategic Asset Allocation: Portfolio Choice for Long-Term Investors, Oxford University Press.

Chiang, Yao-Min, David Hirshleifer, Yiming Qian, and Ann E. Sherman, 2011, Do investors learn from experience? Evidence from frequent IPO investors, Review of Financial Studies 24, 1560-1589. 
Choi, James J., David Laibson, Brigitte C. Madrian, and Andrew Metrick, 2009, Reinforcement learning and savings behavior, Quarterly Journal of Economics 124, 1639-1674.

Cohen, Randolph B., Paul A. Gompers, and Tuomo Vuolteenaho, 2002, Who underreacts to cash-flow news? Evidence from trading between individuals and institutions, Journal of Financial Economics 66, 409-62.

Cohen, Randolph B., Christopher Polk, and Bernhard Silli, 2010, Best ideas, unpublished paper, Harvard Business School, London School of Economics, and Goldman Sachs Group, Inc.

Cohn, Richard A., Wilbur G. Lewellen, Ronald C. Lease and Gary G. Schlarbaum, 1975, Individual investor risk aversion and investment portfolio composition, Journal of Finance 30, 605-620.

Coval, Joshua, David Hirshleifer, and Tyler Shumway, 2005, Can individual investors beat the market?, Unpublished paper, available online at

http://papers.ssrn.com/sol3/papers.cfm?abstract_id=364000.

Cremers, Martijn and Antti Petajisto, 2009, How active is your fund manager? A new measure that predicts performance, Review of Financial Studies 22, 3329-3365.

Cronqvist, Henrik, Stephan Siegel, and Frank Yu, 2013, Value versus growth investing: Why do different investors have different styles?, unpublished paper, available online at

http://papers.ssrn.com/sol3/papers.cfm?abstract_id=2351123.

Daniel, Kent, David Hirshleifer, and Avanidhar Subrahmanyam, 1998, Investor psychology and security market under- and overreactions, Journal of Finance 53, 1839-1885.

De, Sankar, Naveen R. Gondhi, and Bhimasankaram Pochiraju, 2010, Does sign matter more than size? An investigation into the source of investor overconfidence, unpublished paper, Indian School of Business, Hyderabad, available online at 
http://papers.ssrn.com/sol3/papers.cfm?abstract_id=1657926.

Dhar, Ravi, and Ning Zhu, 2006, Up close and personal: An individual level analysis of the disposition effect, Management Science, 52, 726-740.

Falkenstein, Eric G., 1996, Preferences for stock characteristics as revealed by mutual fund portfolio holdings, Journal of Finance 51, 111-135.

Fama, Eugene F. and Kenneth R. French, 1993, Common risk factors in the returns on stocks and bonds, Journal of Financial Economics 33, 3-56.

Fama, Eugene F. and Kenneth R. French, 2002, Testing tradeoff and pecking order predictions about dividends and debt, Review of Financial Studies 15, 1-33.

Feng, Lei and Mark S. Seasholes, 2005, Do investor sophistication and trading experience eliminate behavioral biases in financial markets?, Review of Finance 9, 305-351.

Froot, Kenneth, Paul O'Connell, and Mark Seasholes, 2001, The portfolio flows of international investors, Journal of Financial Economics 59, 151-193

Froot, Kenneth and Melvyn Teo, 2008, Style investing and institutional investors, Journal of Financial and Quantitative Analysis 43, 883-906.

Gervais, Simon and Terrance Odean, 2001, Learning to be overconfident, Review of Financial Studies 14, 1-27.

Goetzmann, William N. and Massimo Massa, 2002, Daily momentum and contrarian behavior of index fund investors, Journal of Financial and Quantitative Analysis 37, 375-389.

Gomes, Francisco and Alexander Michaelides, 2008, Asset pricing with limited risk sharing and heterogeneous agents, Review of Financial Studies 21, 415-448.

Gompers, Paul A. and Andrew Metrick, 2001, Institutional ownership and equity prices, Quarterly Journal of Economics 116, 229-260. 
Greenwood, Robin and Stefan Nagel, 2009, Inexperienced investors and bubbles, Journal of Financial Economics 93, 239-258.

Grinblatt, Mark and Matti Keloharju, 2000, The investment behavior and performance of various investor types: a study of Finland's unique data set, Journal of Financial Economics 55, 43-67.

Grinblatt, Mark, Matti Keloharju, and Juhani Linnainmaa, 2011, IQ and stock market participation, Journal of Finance 66, 2121-2164.

Grinblatt, Mark, Ikaheimo, Seppo, Keloharju, Matti and Knüpfer, Samuli, 2012, IQ and mutual fund choice, unpublished paper, available online at http://ssrn.com/abstract $=2021957$

Grinblatt, M., and S. Titman, 1993, Performance measurement without benchmarks: An examination of mutual fund returns, Journal of Business 66, 47-68.

Grossman, Sanford J. and Joseph E. Stiglitz, 1980, On the impossibility of informationally efficient markets, American Economic Review 70, 393-408.

Guiso, Luigi, and Paolo Sodini, 2013, Household finance: An emerging field, Chapter 21 in George Constantinides, Milton Harris, and Rene Stulz eds., Handbook of the Economics of Finance, Volume 2B, North-Holland, 1397-1531.

Han, Bing and Alok Kumar, 2013, Speculative retail trading and asset prices, Journal of Financial and Quantitative Analysis 48, 377-404.

Hong, H., J. D. Kubik, and J. C. Stein, 2004, Social interaction and stock market participation, Journal of Finance 59, 137-63.

Huang, Xing, 2013, Mark Twain's cat: Industry investment experience, categorical thinking, and stock selection, unpublished paper, Michigan State University. 
Ivkovic, Zoran, Clemens Sialm, and Scott J. Weisbenner, 2008, Portfolio concentration and the performance of individual investors, Journal of Financial and Quantitative Analysis 43, 613-55.

Ivkovic, Zoran, and Scott J. Weisbenner, 2005, Local does as local is: Information content of the geography of individual investors' common stock investments, Journal of Finance $60,267-306$.

Ivkovic, Zoran, and Scott Weisbenner, 2007, Information diffusion effects in individual investors' common stock purchases: Covet thy neighbors' investment choices, Review of Financial Studies 20:1327-57.

Kaniel, Ron, Gideon Saar, and Sheridan Titman, 2008, Individual investor trading and stock returns, Journal of Finance, 63, 273-310.

Kaustia, Markku and Samuli Knüpfer, 2008, Do investors overweight personal experience? Evidence from IPO subscriptions, Journal of Finance 63, 2679-2702.

Kelley, Eric K. and Paul C. Tetlock, 2013, How wise are crowds? Insights from retail orders and stock returns, Journal of Finance 68, 1229-1265.

Kelly, Morgan, 1995, All their eggs in one basket: Portfolio diversification of U.S. households, Journal of Economic Behavior and Organization 27, 87-96.

Kempf, Elisabeth, Alberto Manconi, and Oliver Spalt, 2013, Learning by doing: The value of experience and the origins of skill for mutual fund managers, unpublished paper, Tilburg University and CentER.

Kovtunenko, Boris and Nathan Sosner, 2004, Avoidance of small stocks and institutional performance, unpublished paper, Blue Fir Capital and AQR Capital Management, available online at http://papers.ssrn.com/sol3/papers.cfm?abstract_id=1132770.

Kruger, Samuel, 2013, Disagreement and liquidity, unpublished paper, Harvard University. 
Kumar, Alok, 2009, Hard-to-value stocks, behavioral biases, and informed trading, Journal of Financial and Quantitative Analysis, 44, 1375-1401.

Kumar, Alok and George Korniotis, 2011, Do older investors make better investment decisions? Review of Economics and Statistics, 93, 244-265.

Linnainmaa, Juhani, 2011, Why do (some) households trade so much? Review of Financial Studies 24, 1630-1666.

Lusardi, Annamaria and Olivia Mitchell, 2007, Baby boomer retirement security: The roles of planning, financial literacy, and household wealth, Journal of Monetary Economics $54,205-224$.

Mahani, Reza and Dan Bernhardt, 2007, Financial speculators' underperformance: Learning, self-selection, and endogenous liquidity, Journal of Finance 62, 1313-1340.

Malmendier, Ulrike and Stefan Nagel, 2011, Depression babies: Do macroeconomic experiences influence risktaking?, Quarterly Journal of Economics 126, 373-416.

Malmendier, Ulrike and Stefan Nagel, 2012, Learning from inflation experiences, unpublished paper, UC Berkeley and Stanford University.

Martins, Renato, Harminder Singh, and Sukanto Bhattacharya, 2012, What does volume reveal: A study of the Indian single-stock futures market, Indian Journal of Economics \&f Business, 11, 409-419.

Mukherjee, Saptarshi and Sankar De, 2012, Are investors ever rational?, unpublished paper, Indian School of Business, available online at http://papers.ssrn.com/sol3/papers.cfm?abstract_id=2156047.

Nicolosi, Gina, Liang Peng, and Ning Zhu, 2009, Do individual investors learn from their trading experience?, Journal of Financial Markets 12, 317-366. 
Odean, Terrance, 1998, Are investors reluctant to realize their losses? Journal of Finance $53,1775-1798$.

Odean, Terrance, 1999, Do investors trade too much? American Economic Review 89, $1279-1298$.

O'Hara, Maureen, 2003, Presidential address: Liquidity and price discovery, Journal of Finance 58, 1335-1354.

Pastor, Lubos and Pietro Veronesi, 2009, Learning in financial markets, Annual Review of Financial Economics 1, 361-381.

Ranguelova, Elena, 2001, Disposition effect and firm size: New evidence on individual investor trading activity, unpublished paper, available online at http://ssrn.com/abstract $=293618$.

Schlarbaum, Gary, Wilbur Lewellen, and Ronald Lease, 1978, Realized returns on common stock investments: The experience of individual investors, Journal of Business 51, $299-325$.

Seru, Amit, Tyler Shumway, and Noah Stoffman, 2010, Learning by trading, Review of Financial Studies 23, 705-739.

Shefrin, Hersh and Meir Statman, 1985, The disposition to sell winners too early and ride losers too long: Theory and evidence, Journal of Finance 40, 777-790.

Shleifer, Andrei, 2000, Inefficient Markets: An Introduction to Behavioral Finance, Oxford University Press.

Siegel, Jeremy J., 2007, Stocks for the Long Run, 4th ed., McGraw-Hill.

Stambaugh, Robert, 1999, Predictive regressions, Journal of Financial Economics 54, 375421. 
Statman, Meir, Steven Thorley, and Keith Vorkink, 2006, Investor overconfidence and trading volume, Review of Financial Studies 19, 1531-1565.

Strahilevitz, Michal Ann, Terrance Odean, and Brad M. Barber, 2011, Once burned, twice shy: How naïve learning, counterfactuals, and regret affect the repurchase of stocks previously sold, Journal of Marketing Research 48, S102-S120.

Vashishtha, Ashutosh, and Satish Kumar, Development of financial derivatives market in India - a case study, 2010, International Research Journal of Finance and Economics, $37,15-29$.

Wermers, Russ, 2000, Mutual fund performance: An empirical decomposition into stockpicking talent, style, transactions costs, and expenses, Journal of Finance 55, 16551695. 


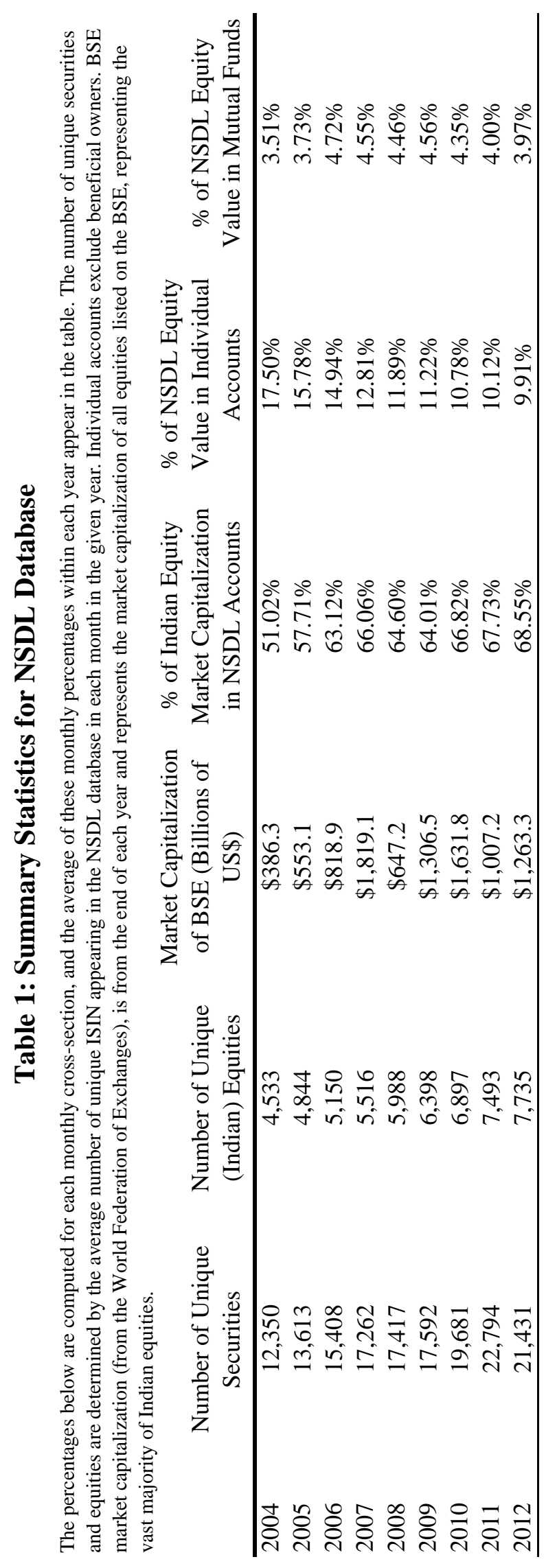




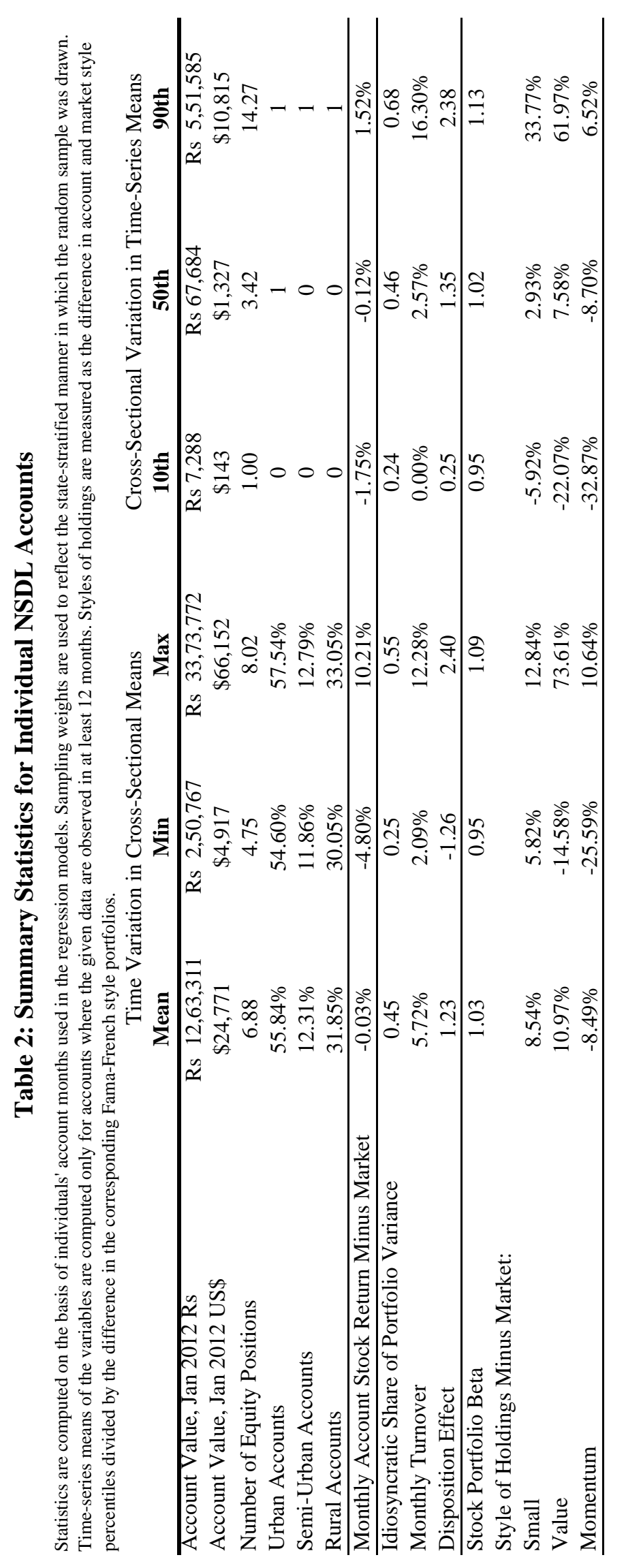




\section{Table 3: Individual Investors Behavior Regressions}

Regressions follow Equation (3) using account-months for which the variables used in the regression are defined (disposition effect is defined only where a trade occurs and gains and losses both exist). Investor behaviors $(Y)$ are scaled by the timeseries average of their cross-sectional means. Account value is winsorized below at Rs. 10,000 (approximately \$200 US). For turnover and disposition effect, the lagged 12-month average is used as the lagged behavior control. Panel regressions are run using weights that account for sampling probability and further apply equal weight to each cross-section (month). Standard errors in ( ) are computed from bootstraps of monthly data. Coefficients that are significant at a five percent level are in bold type.

\begin{tabular}{|c|c|c|c|}
\hline $\begin{array}{l}\text { Dependent Variable: } \\
\text { Number of Observations: }\end{array}$ & $\begin{array}{c}\text { Idiosyncratic Share of } \\
\text { Portfolio Variance } \\
\text { 3,444,690 }\end{array}$ & $\begin{array}{r}\text { Turnover } \\
3,444,690\end{array}$ & $\begin{array}{c}\text { Disposition Effect } \\
439,974\end{array}$ \\
\hline $\begin{array}{l}\text { Account Age, Piecewise Linear } \\
\text { Form }\end{array}$ & & See Figure & \\
\hline $\begin{array}{l}\text { Account Performance Feedback, } \\
\text { by Time Since Event } \\
\text { Behavior-Specific Feedback, by } \\
\text { Time Since Event }\end{array}$ & |-------------------------. & See Figure & ---------------------- \\
\hline Log Account Value & $\begin{array}{r}\mathbf{- 0 . 0 1 5} \\
(0.001)\end{array}$ & $\begin{array}{c}\mathbf{0 . 1 2 6} \\
(0.013)\end{array}$ & $\begin{array}{c}\mathbf{- 0 . 0 3 7} \\
(0.015)\end{array}$ \\
\hline Lagged Investor Behavior & $\begin{array}{c}\mathbf{0 . 7 7 6} \\
(0.008)\end{array}$ & $\begin{array}{r}\mathbf{0 . 3 6 9} \\
(0.018) \\
\end{array}$ & $\begin{array}{r}\mathbf{- 0 . 1 4 9} \\
(0.011) \\
\end{array}$ \\
\hline
\end{tabular}

\section{Table 4: Individual Investors Net Style Demand Regressions}

Regressions follow Equation (3) using account-months for which the variables used in the regression are defined. Investor net style demands $(Y)$ are scaled by the spread in percentiles between the Fama French long and short portfolios based on the corresponding styles. Account value is winsorized below at Rs. 10,000. Panel regressions are run using weights that account for sampling probability and further apply equal weight to each cross-section (month). Standard errors in ( ) are computed from bootstraps of monthly data. Coefficients that are significant at a five percent level are in bold type.

\begin{tabular}{|c|c|c|c|}
\hline $\begin{array}{l}\text { Dependent Variable: } \\
\text { Number of Observations: }\end{array}$ & $\begin{array}{c}\text { Net Small Demand } \\
3,599,452\end{array}$ & $\begin{array}{l}\text { Net Value Demand } \\
\text { 3,599,452 }\end{array}$ & $\begin{array}{c}\text { Net Momentum } \\
\text { Demand } \\
3,599,452\end{array}$ \\
\hline $\begin{array}{l}\text { Account Age, Piecewise Linear } \\
\text { Form }\end{array}$ & -------י & ----See Figure 4---- & \\
\hline $\begin{array}{l}\text { Account Performance Feedback, } \\
\text { by Time Since Event } \\
\text { Style-Specific Feedback, by } \\
\text { Time Since Event }\end{array}$ & -------------------. & -----See Figure 5---- & \\
\hline Log Account Value & $\begin{array}{c}\mathbf{0 . 0 7 7 \%} \\
(0.018 \%)\end{array}$ & $\begin{array}{l}\mathbf{- 0 . 1 1 7 \%} \\
(0.031 \%)\end{array}$ & $\begin{array}{c}0.019 \% \\
(0.026 \%)\end{array}$ \\
\hline $\begin{array}{l}\text { Lagged Portfolio Style } \\
\text { Percentile }\end{array}$ & $\begin{array}{l}\mathbf{- 0 . 0 7 8 \%} \\
(0.005 \%)\end{array}$ & $\begin{array}{l}\mathbf{- 0 . 1 1 8 \%} \\
(0.006 \%)\end{array}$ & $\begin{array}{l}\mathbf{- 0 . 0 5 2 \%} \\
(0.003 \%)\end{array}$ \\
\hline
\end{tabular}




\section{Table 5: Decomposition of the Difference in Returns on Old and New Accounts}

Over our sample period, we form zero cost portfolios as differences in average portfolio weights between the cohorts (determined by quintile rankings on age) of investors mentioned in the column headers (e.g., oldest minus average (middle quintile)). These weights pertain to 2,677 stocks with market capitalization of at least Rs. 500 million (approximately $\$ 10$ million US). In the top panel of the table, we relate these portfolio weights to stock characteristics listed below using Fama MacBeth regressions, where all characteristics used except market beta, stock age, and the IPO control are measured in rank-normalized form, and coefficients are multiplied by 1000 . The bottom panel decomposes total returns into timing and selection effects -- Section 6.2 of the paper provides details. Standard errors in ( ) are computed by bootstrap, and statistically significant coefficients at the five and ten percent level are indicated by bold and italicized type respectively.

Number of Observations (Stock-Months): 103,509

\begin{tabular}{|c|c|c|c|}
\hline $\begin{array}{l}\text { Zero-Cost Portfolios: } \\
\text { Portfolio Tilts }\end{array}$ & $\begin{array}{c}\text { Oldest minus Newest } \\
{[1]}\end{array}$ & $\begin{array}{l}\text { Oldest minus Average } \\
{[2]}\end{array}$ & $\begin{array}{c}\text { Average minus Newest } \\
{[3]}\end{array}$ \\
\hline \multirow[t]{2}{*}{ Market Beta } & -0.547 & -0.393 & -0.154 \\
\hline & $(0.568)$ & $(0.224)$ & $(0.428)$ \\
\hline \multirow[t]{2}{*}{1 / Market Capitalization } & 0.318 & 0.448 & -0.130 \\
\hline & $(0.233)$ & $(0.185)$ & $(0.272)$ \\
\hline \multirow[t]{2}{*}{ Book-Market } & 0.171 & 0.100 & 0.071 \\
\hline & $(0.143)$ & $(0.095)$ & $(0.179)$ \\
\hline \multirow[t]{2}{*}{ Momentum (Lagged) Returns } & -0.003 & 0.113 & -0.116 \\
\hline & $(0.340)$ & $(0.255)$ & $(0.175)$ \\
\hline \multirow[t]{2}{*}{ Stock Turnover } & -0.908 & -0.237 & -0.671 \\
\hline & $(0.262)$ & $(0.306)$ & $(0.396)$ \\
\hline \multirow[t]{2}{*}{ Beneficial Ownership } & -0.604 & -0.457 & -0.147 \\
\hline & $(0.367)$ & $(0.192)$ & $(0.246)$ \\
\hline \multirow[t]{2}{*}{ Institutional Ownership } & 0.919 & 0.447 & 0.472 \\
\hline & $(0.356)$ & $(0.162)$ & $(0.438)$ \\
\hline \multirow[t]{2}{*}{ Log (1 + Stock Age $)$} & 0.010 & 0.216 & -0.207 \\
\hline & $(0.075)$ & $(0.118)$ & $(0.104)$ \\
\hline Large IPOs (Market Cap if & -13.358 & -0.733 & -12.625 \\
\hline Age $<$ One Year) & $(3.723)$ & $(0.358)$ & $(3.625)$ \\
\hline \multicolumn{4}{|l|}{ Return Decomposition } \\
\hline \multirow[t]{2}{*}{ Stock Characteristic Selection } & 8.52 & 3.37 & 5.15 \\
\hline & $(5.54)$ & $(2.34)$ & (3.54) \\
\hline \multirow[t]{2}{*}{ Additional Stock Selection } & 12.90 & 4.72 & 8.19 \\
\hline & $(14.55)$ & (5.97) & $(11.15)$ \\
\hline \multirow[t]{2}{*}{ Stock Characteristic Timing } & -9.63 & 1.16 & -10.79 \\
\hline & $(11.13)$ & (5.73) & $(7.17)$ \\
\hline \multirow[t]{2}{*}{ Additional Stock Timing } & 26.60 & -0.41 & 27.02 \\
\hline & $(21.24)$ & $(7.35)$ & $(21.53)$ \\
\hline \multirow[t]{2}{*}{ Total Difference in Returns } & 38.40 & 8.83 & 29.56 \\
\hline & $(28.34)$ & $(10.87)$ & $(24.42)$ \\
\hline
\end{tabular}




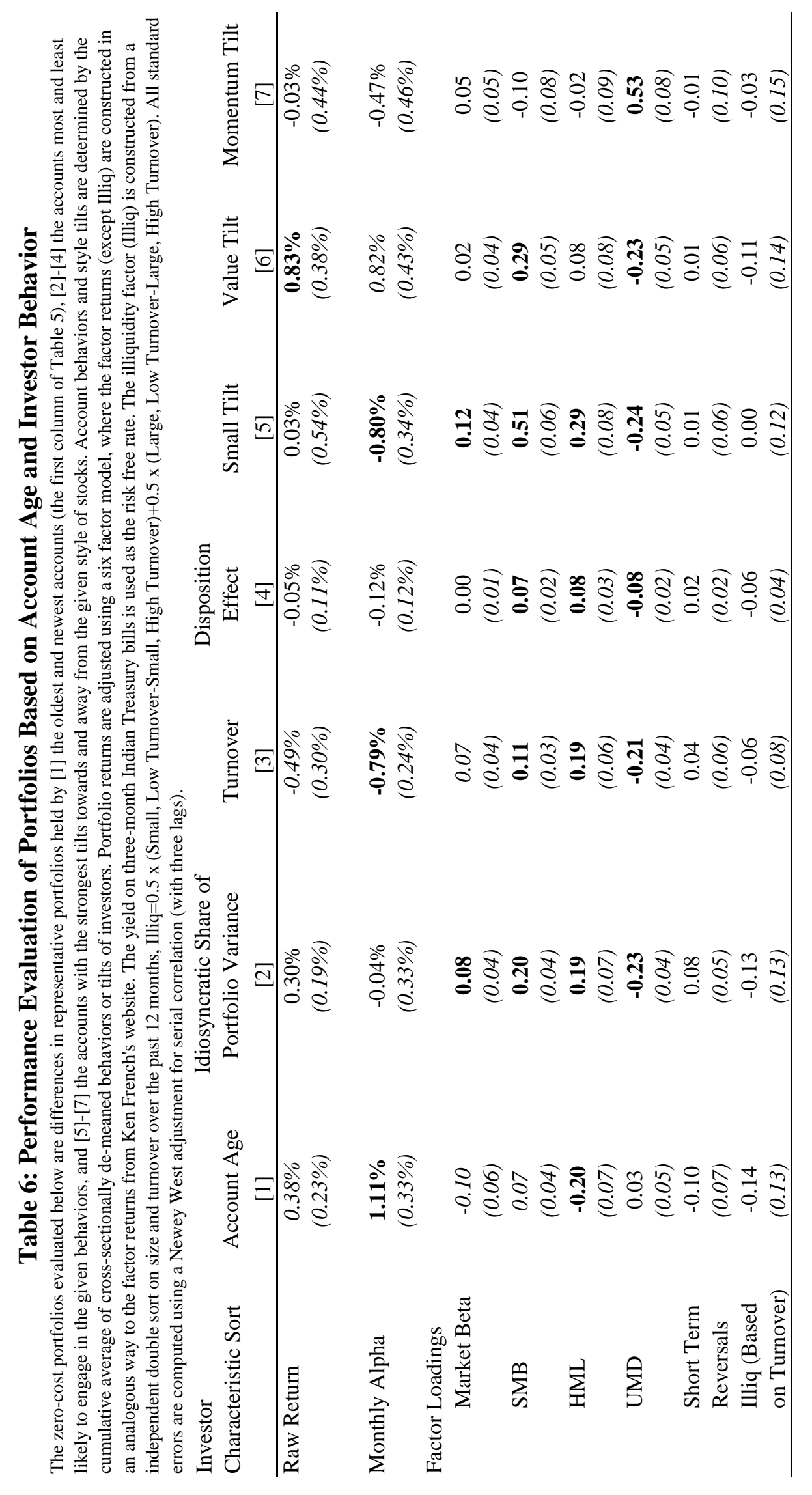




\section{Table 7: Stock Return Regressions Using Stock and Stockholders' Characteristics}

For each of 3,614 stocks with at least 10 individual investors from our sample, we regress monthly stock returns over our sample period on characteristics of the average investor in that stock at that point in time, and characteristics of the stock. For each investor, characteristics at a point in time are given by the cumulative average of the investors' cross-sectionally demeaned behavior or style tilt. Stock-level investor characteristics, and all stock characteristics except for market beta and stock age are converted to normalized rank form. The regressions below are carried out by the Fama MacBeth procedure, with a Newey West serial correlation adjustment. All coefficients are multiplied by 100, and statistical significance at the five and ten percent level are indicated by bold and italicized type respectively.

Number of Observations (Stock-Months): 194,487

\begin{tabular}{|c|c|c|c|c|}
\hline & & {$[1]$} & {$[2]$} & {$[3]$} \\
\hline \multirow{14}{*}{$\begin{array}{c}\text { Investor } \\
\text { Characteristics }\end{array}$} & Account Age & 1.61 & 0.61 & 0.14 \\
\hline & & $(0.58)$ & $(0.29)$ & $(0.23)$ \\
\hline & Idiosyncratic Share of & & -0.22 & 0.16 \\
\hline & Portfolio Variance & & $(0.32)$ & $(0.34)$ \\
\hline & Portfolio Turnover & & -1.88 & -0.64 \\
\hline & & & $(0.54)$ & $(0.32)$ \\
\hline & Disposition Effect & & -0.16 & -0.12 \\
\hline & & & $(0.29)$ & $(0.25)$ \\
\hline & Small Tilt & & 0.46 & -1.32 \\
\hline & & & (1.29) & $(0.59)$ \\
\hline & Value Tilt & & 1.83 & -0.70 \\
\hline & & & $(0.46)$ & $(0.51)$ \\
\hline & Momentum Tilt & & 0.81 & 0.19 \\
\hline & & & $(0.47)$ & $(0.32)$ \\
\hline \multirow{16}{*}{$\begin{array}{c}\text { Stock } \\
\text { Characteristics }\end{array}$} & Market Beta & & & 0.35 \\
\hline & & & & $(1.30)$ \\
\hline & 1 / Market Capitalization & & & 3.40 \\
\hline & & & & (1.63) \\
\hline & Book-Market & & & 3.91 \\
\hline & & & & $(0.67)$ \\
\hline & Momentum (Lagged) & & & 3.16 \\
\hline & Returns & & & $(0.58)$ \\
\hline & Stock Turnover & & & -1.73 \\
\hline & & & & $(0.41)$ \\
\hline & Beneficial Ownership & & & 0.75 \\
\hline & & & & $(0.33)$ \\
\hline & Institutional Ownership & & & 0.28 \\
\hline & & & & $(0.37)$ \\
\hline & Log (1 + Stock Age $)$ & & & 0.09 \\
\hline & & & & $(0.11)$ \\
\hline
\end{tabular}




\section{Figure 1: Account Age Effects on Investor Behaviors}

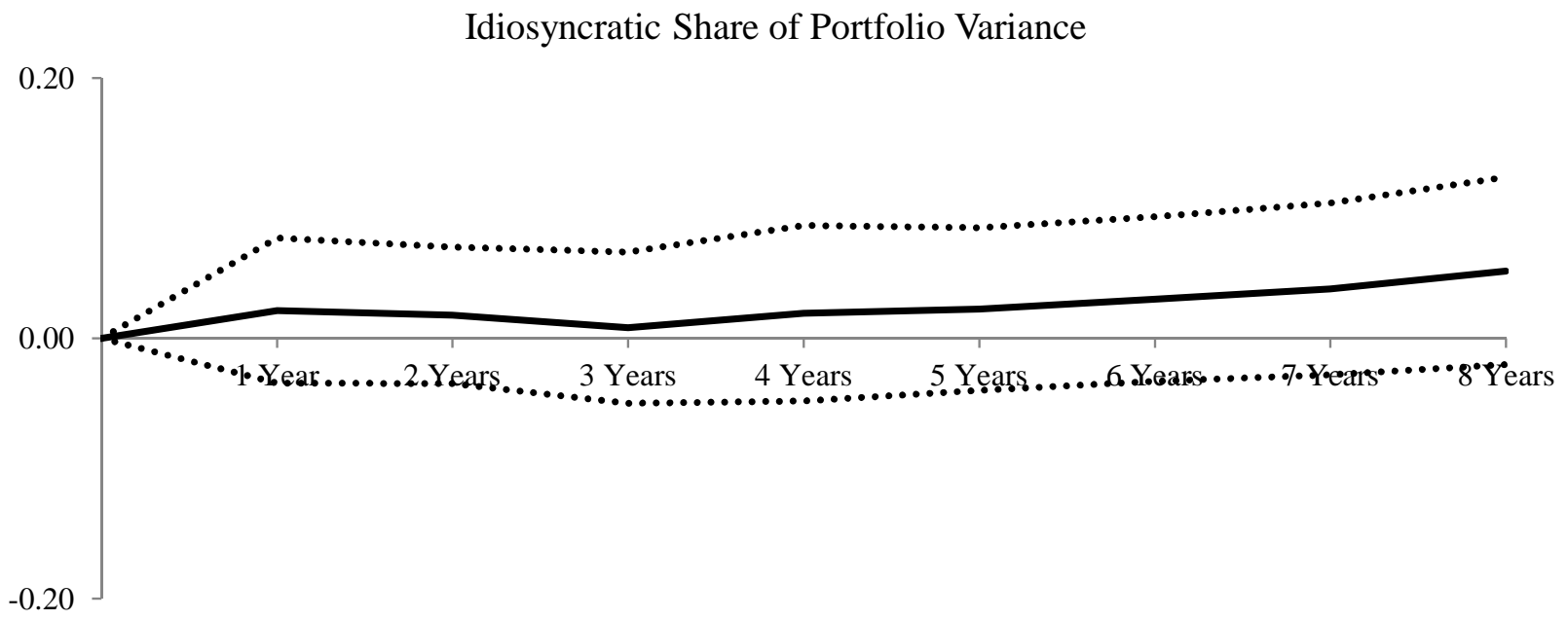

Turnover

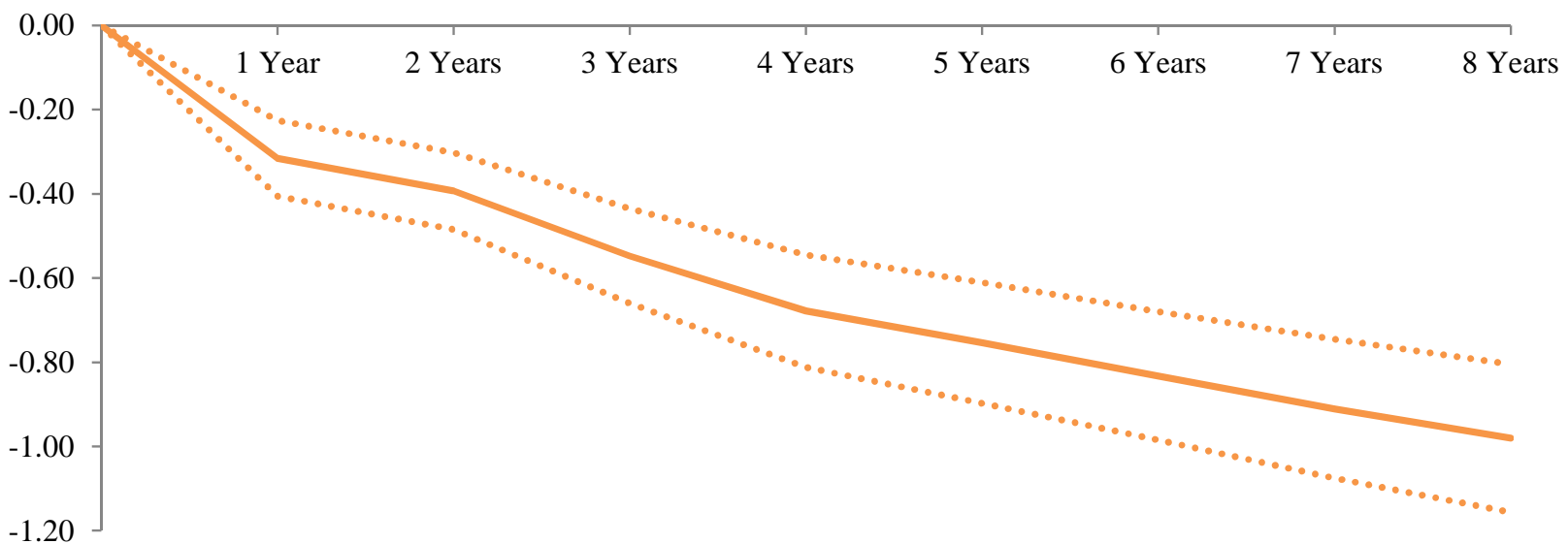

\section{Disposition Effect}

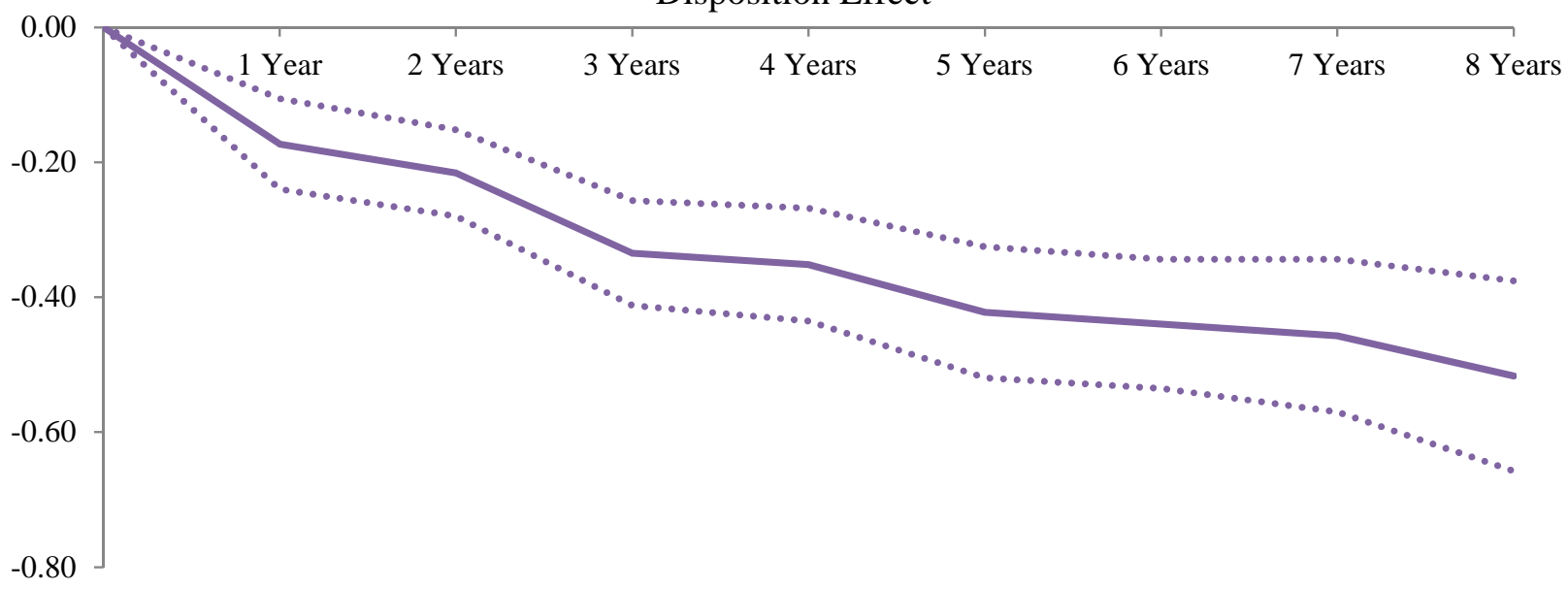

The plots above are produced from investor behavior regressions in Table 3. Values are adjusted to represent the effect of age on the target level of behavior (scaled relative to the mean level of the given behavior). Specifically, point estimates given by the regression are divided by one minus the coefficient on the lagged dependent variable. Dotted lines represent $95 \%$ confidence intervals. 


\section{Figure 2: Feedback Effects on Investing Behavior Account Performance Feedback (Left) and Behavior-Specific Feedback (Right)}

Idiosyncratic Share of Portfolio Variance
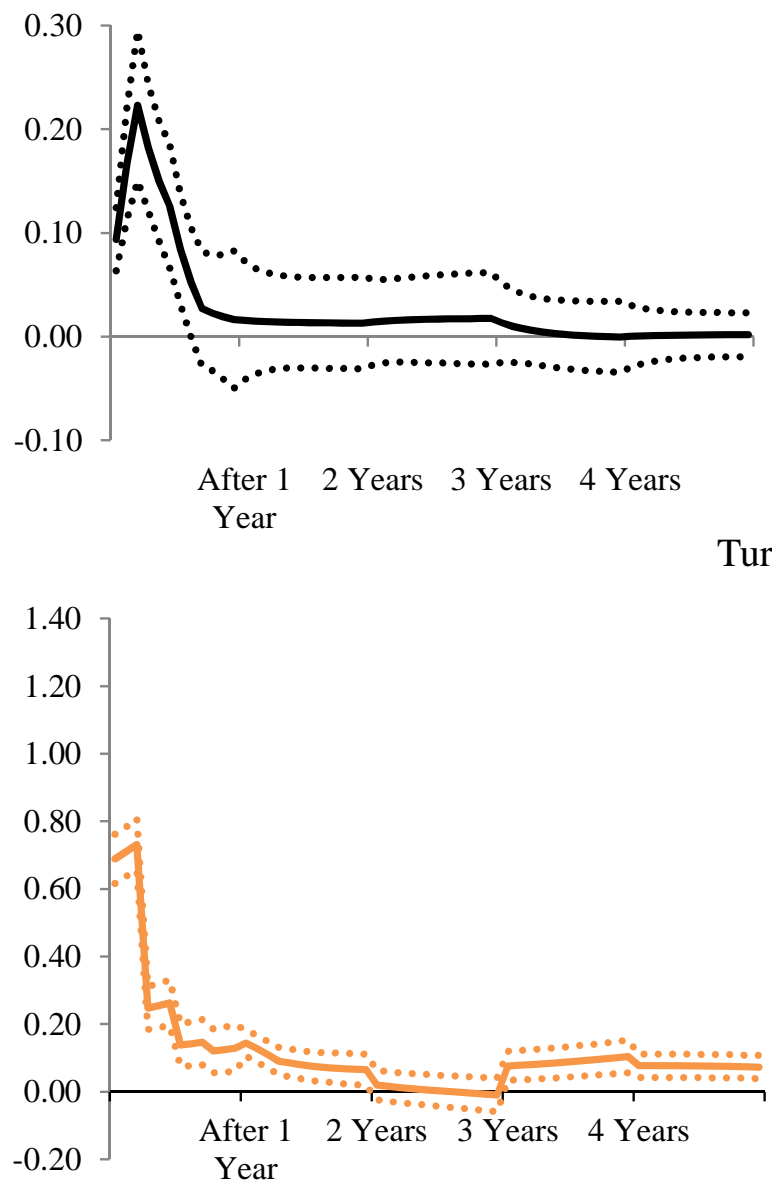

Turnover

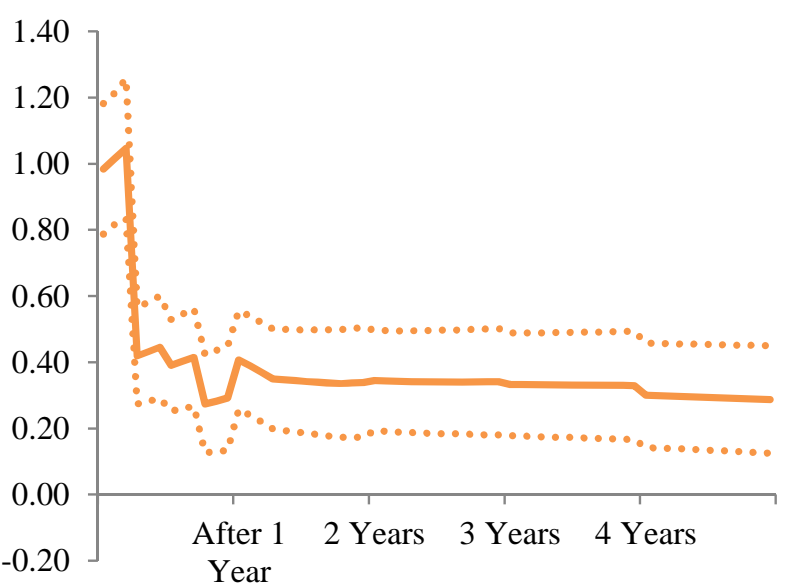

Disposition Effect
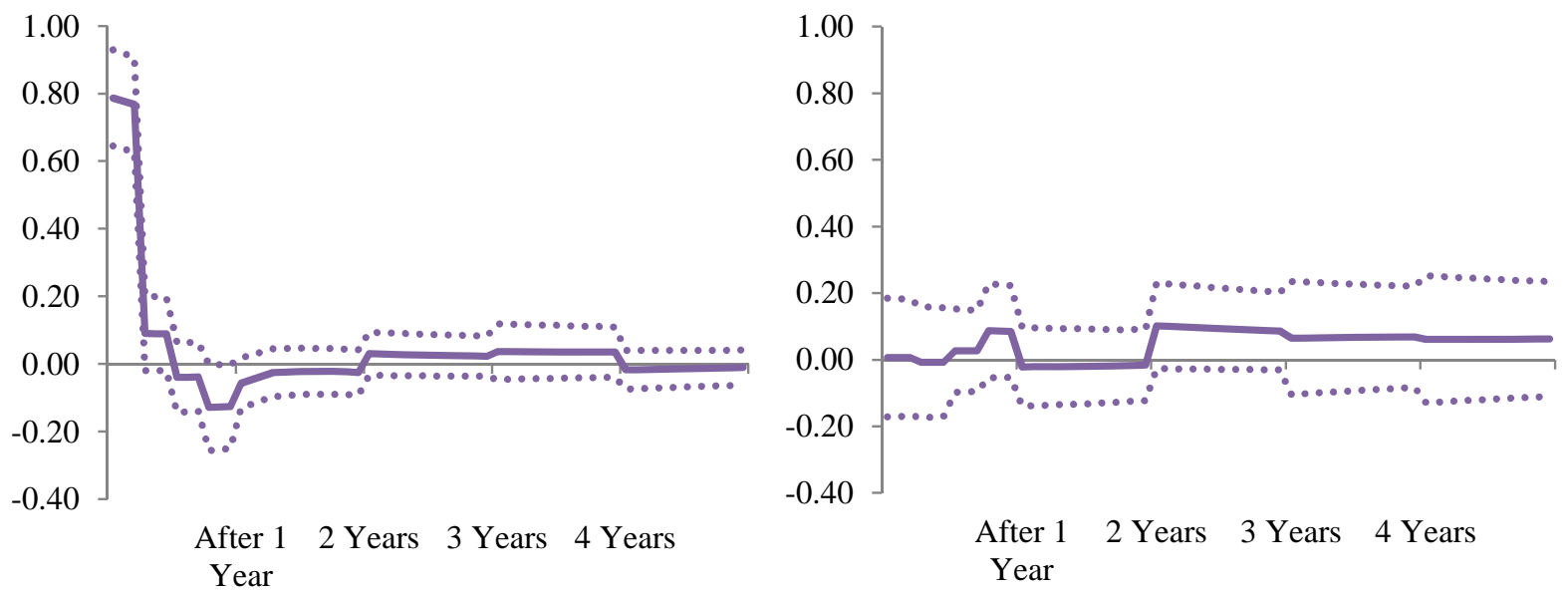

Plots are impulse responses of investor behavior to a unit (100\%) shock to either performance feedback or behaviorspecific feedback. Responses are generated from investor behavior regressions in Table 3, making use of coefficients on both feedback and lagged behavior. Only one plot appears for idiosyncratic share of portfolio variance, as account outperformance is also used as a measure of idiosyncratic-variance share specific feedback. Dotted lines represent $95 \%$ confidence intervals. 
Figure 3: Evolution in Investor Behaviors from Age and Feedback Effects

10th, Median, and 90th Percentile (light to dark) of Accounts Opened December 2003

Idiosyncratic Share of Portfolio Variance

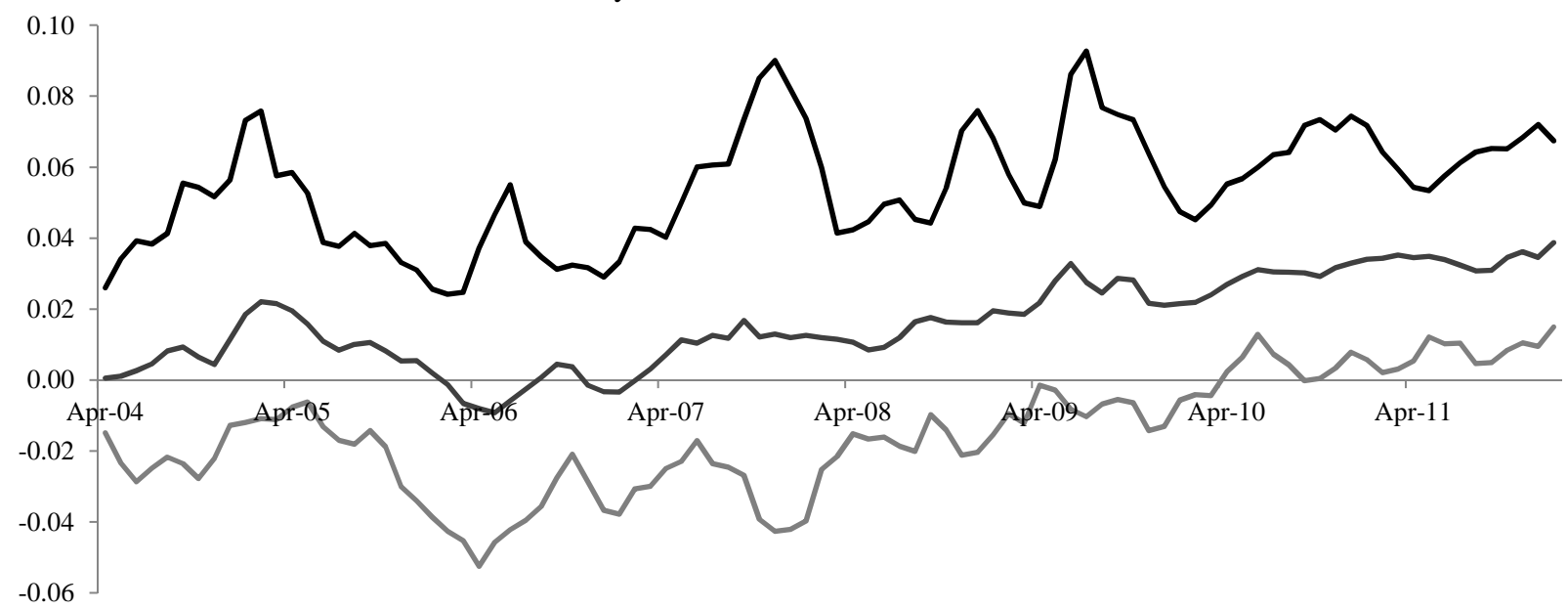

Turnover

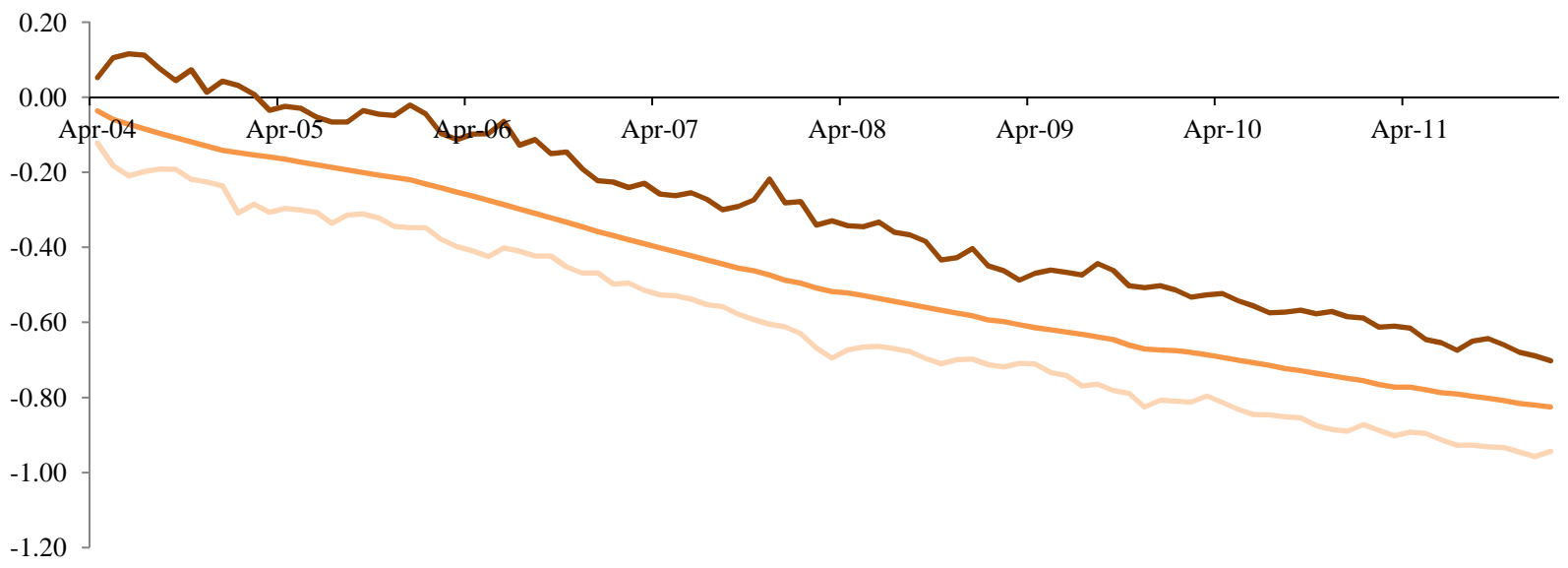

Disposition Effect

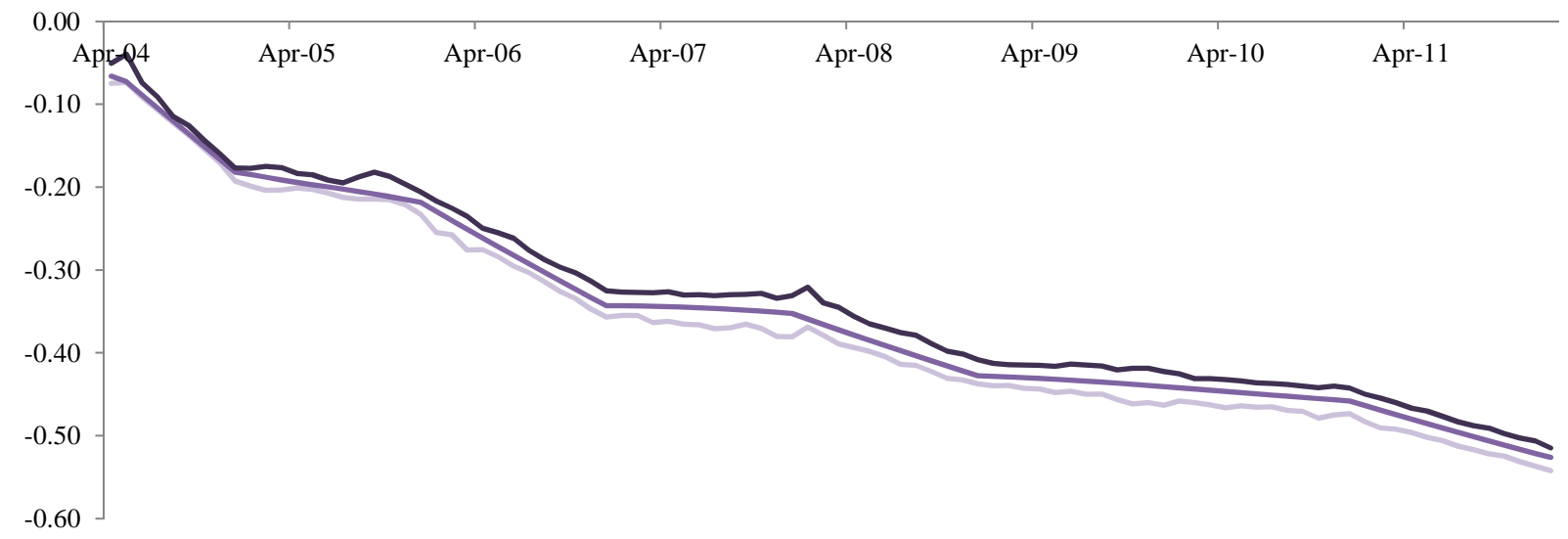

The plots fit age effects, feedback effects, and lagged behavior coefficients from investor behavior regressions in Table 3 with the actual age and feedback received by individual investor accounts opened in December 2003. The 10th, 50th, and 90th percentiles of the simulated distribution appear above. 


\section{Figure 4: Account Age Effects on Net Style Demand}
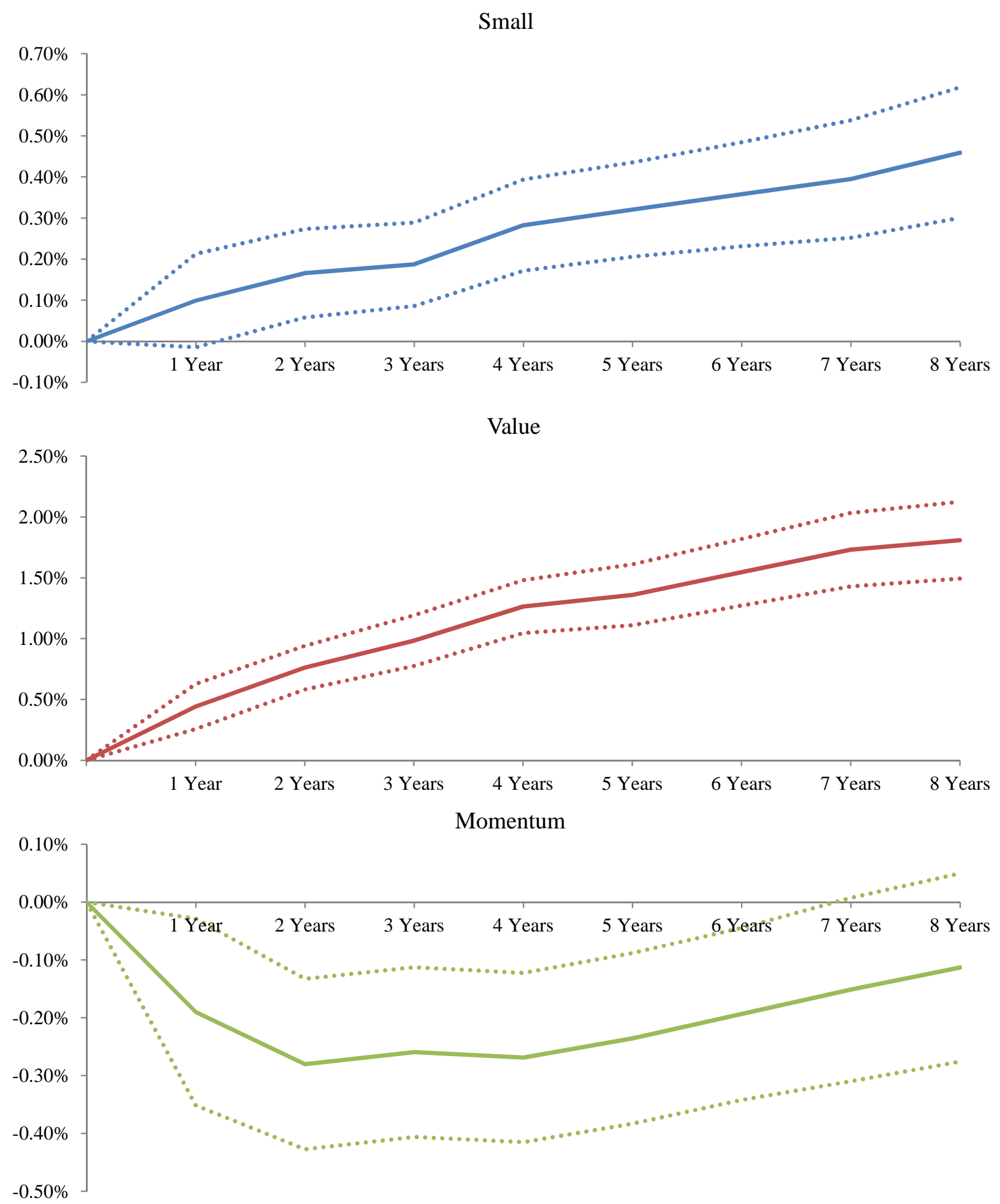

The plots above are produced from investor net style demand regressions in Table 4. Dotted lines represent 95\% confidence intervals. 


\section{Figure 5: Account Performance Feedback Effect on Net Style Demand Response (Left) and Cumulative Response (Right)}

Small
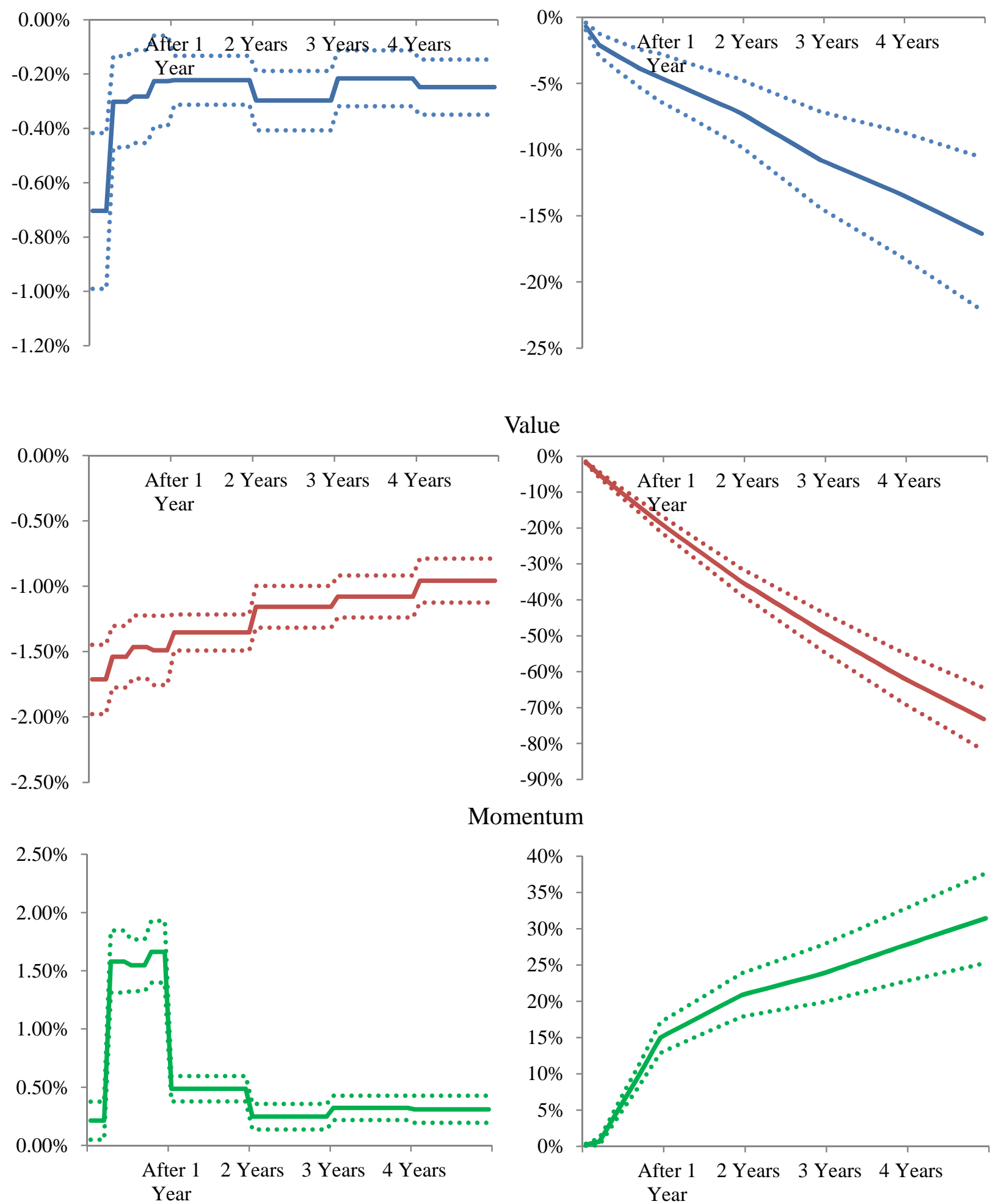

Momentum

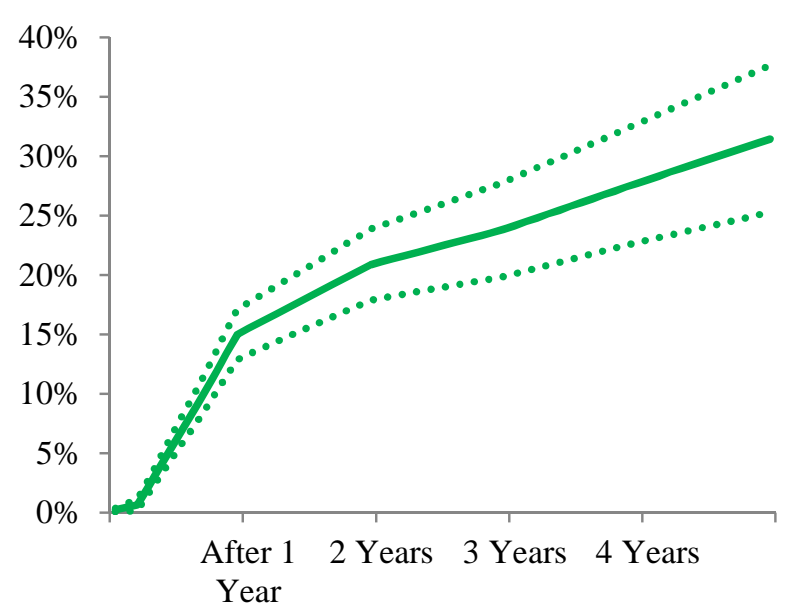

Plots are produced from investor net style demand regressions in Table 4. Dotted lines represent 95\% confidence intervals. 


\section{Figure 6: Style Feedback Effect on Net Style Demand Response (Left) and Cumulative Response (Right)}
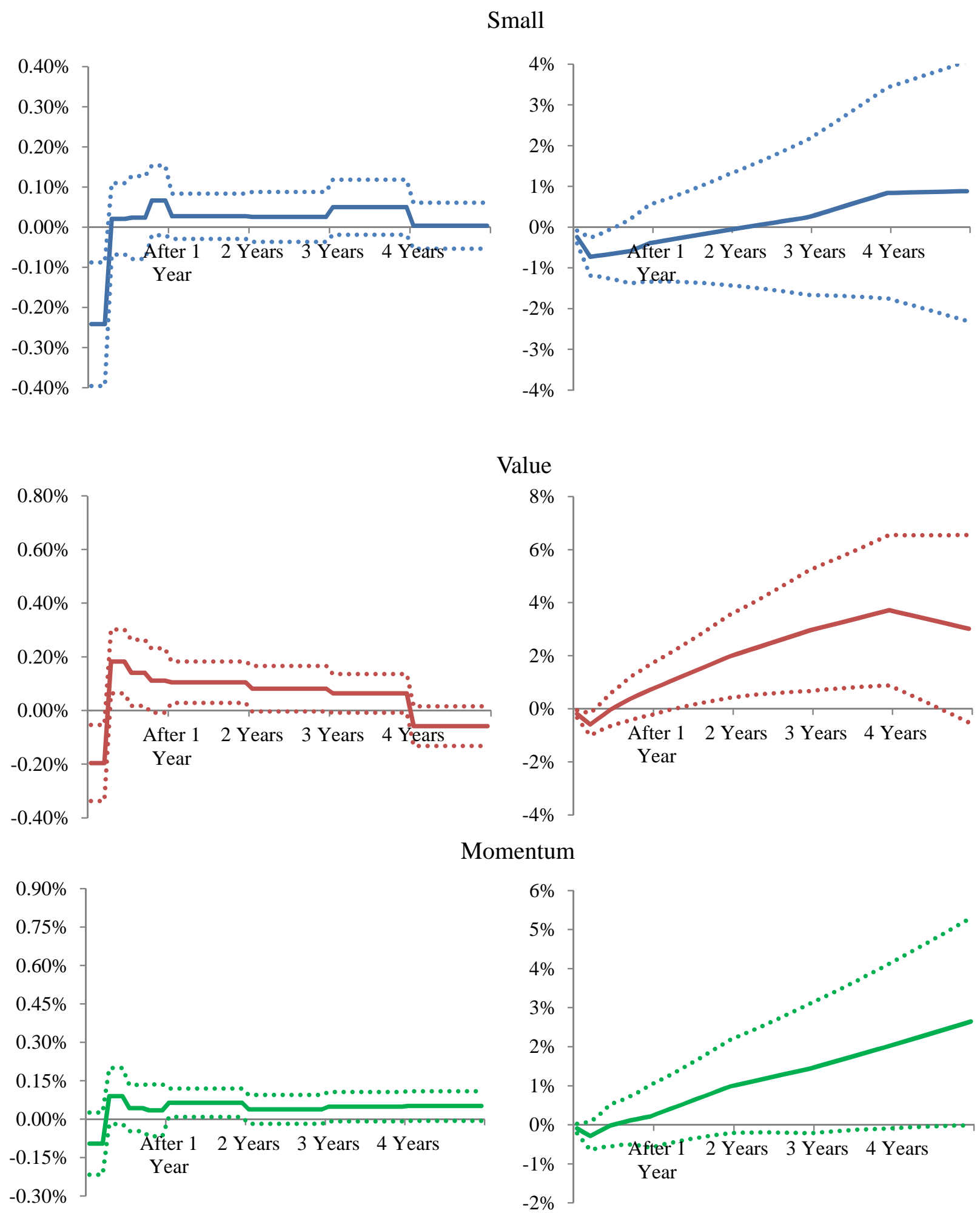

Momentum

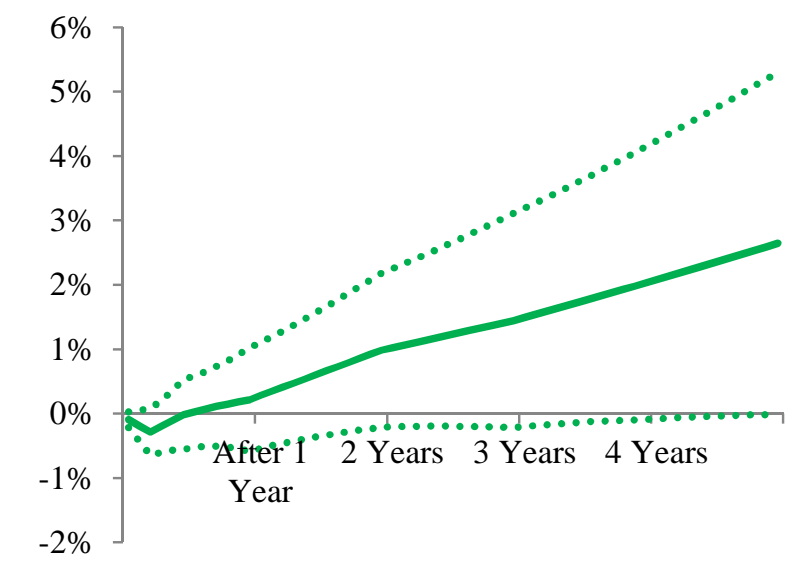

Plots are produced from investor net style demand regressions in Table 4. Dotted lines represent 95\% confidence intervals. 
Figure 7: Evolution in Net Style Demand from Age and Feedback Effects

Net Demand (Left) and Cumulative Net Demand (Right)

10th, Median, and 90th Percentile of Accounts Opened Dec. 2003
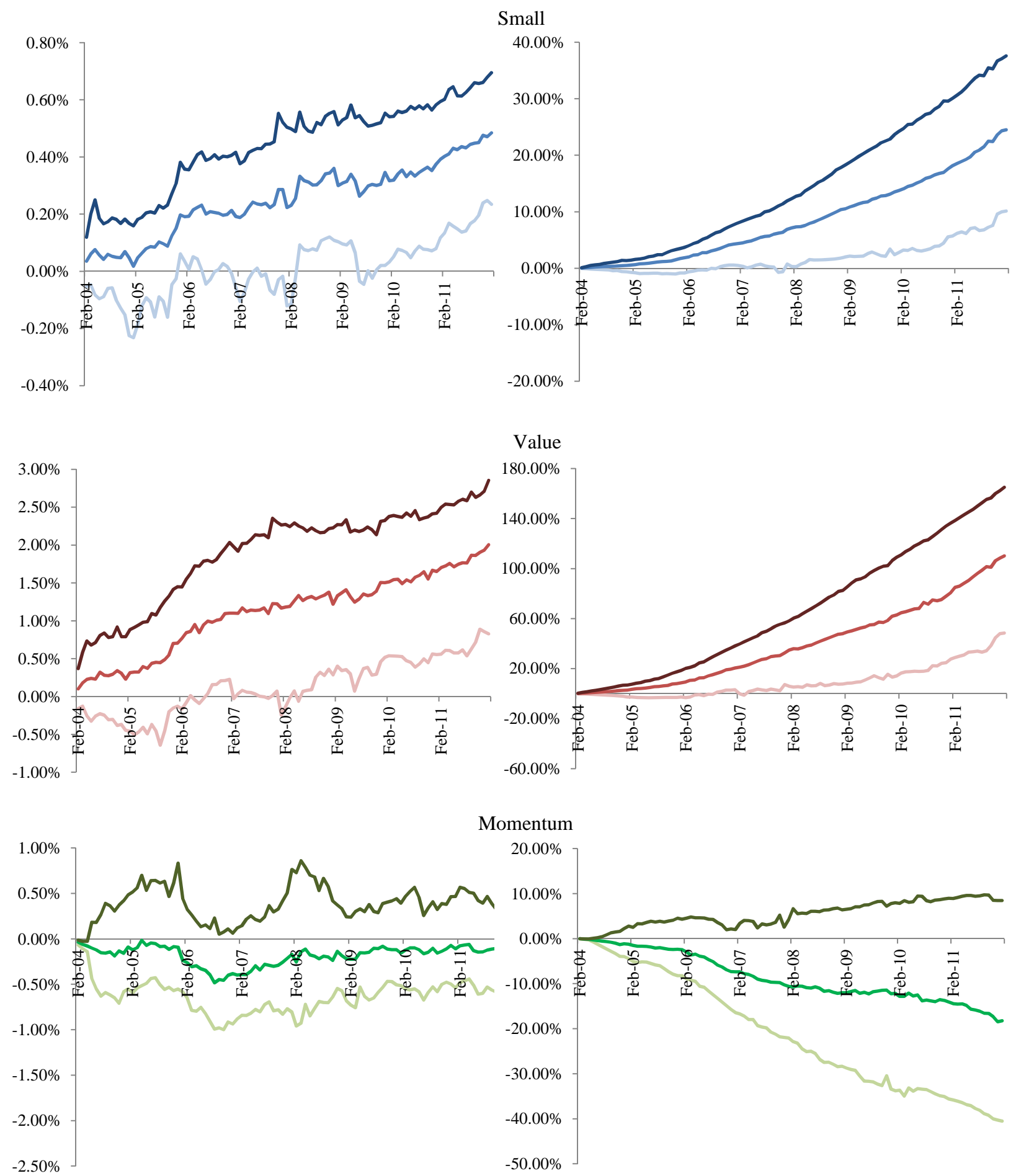

The plots fit age and feedback effects from investor net style demand regressions in Table 4 with the actual age and feedback received by individual investor accounts opened in December 2003. The 10th, 50th, and 90th percentiles of the simulated distribution appear above. 
Figure 8: Top: Account Age Effects on Account Returns (bp/mo) Bottom: Cumulative Excess Equity Returns to Old and New Accounts
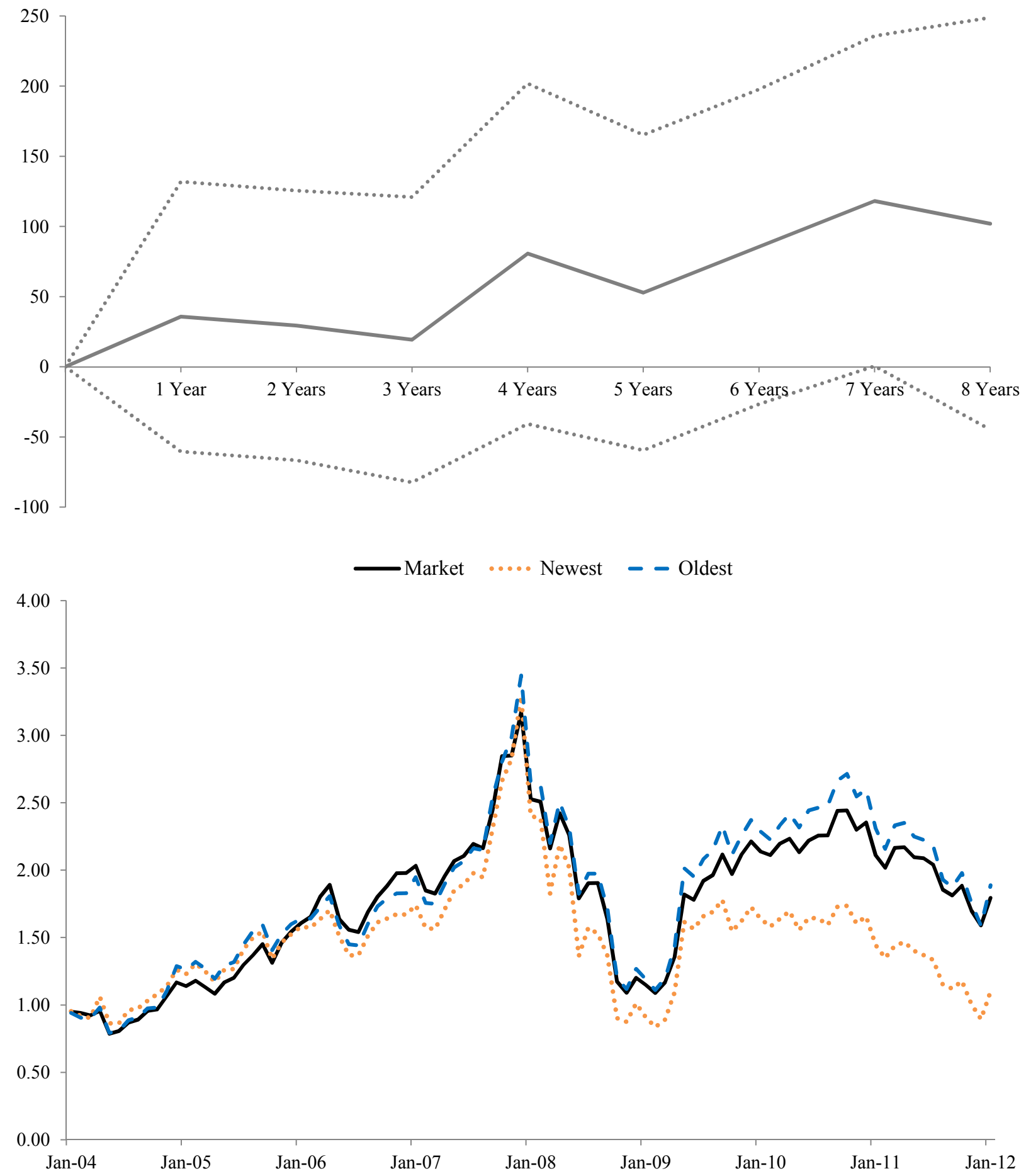

Top: The plotted series represents piecewise linear age effects from the regression $R_{i t}-R_{t}=s_{i}+\beta\left(A_{i t}-A_{t}\right)+\varepsilon_{i t}$, where the break-points in piecewise linear age occur at years one, two, three, four, five, and seven. Dotted lines represent the $95 \%$ confidence interval.

Bottom: Oldest and newest reflect representative portfolios of individual investors in the oldest and newest quintile of accounts present in the month. Excess returns are produced by subtracting the yield on three-month Indian Treasury bills from the portfolios. 